\title{
Parameterization of cloud droplet formation for global and regional models: including adsorption activation from insoluble CCN
}

\author{
P. Kumar ${ }^{1}$, I. N. Sokolik ${ }^{2}$, and A. Nenes ${ }^{1,2}$ \\ ${ }^{1}$ School of Chemical and Biomolecular Engineering, Georgia Institute of Technology, Atlanta, GA, 30332, USA \\ ${ }^{2}$ School of Earth and Atmospheric Sciences, Georgia Institute of Technology Atlanta, GA, 30332, USA
}

Received: 22 July 2008 - Published in Atmos. Chem. Phys. Discuss.: 8 September 2008

Revised: 23 March 2009 - Accepted: 23 March 2009 - Published: 7 April 2009

\begin{abstract}
Dust and black carbon aerosol have long been known to exert potentially important and diverse impacts on cloud droplet formation. Most studies to date focus on the soluble fraction of these particles, and overlook interactions of the insoluble fraction with water vapor (even if known to be hydrophilic). To address this gap, we developed a new parameterization that considers cloud droplet formation within an ascending air parcel containing insoluble (but wettable) particles externally mixed with aerosol containing an appreciable soluble fraction. Activation of particles with a soluble fraction is described through well-established Köhler theory, while the activation of hydrophilic insoluble particles is treated by "adsorption-activation" theory. In the latter, water vapor is adsorbed onto insoluble particles, the activity of which is described by a multilayer Frenkel-Halsey-Hill (FHH) adsorption isotherm modified to account for particle curvature. We further develop FHH activation theory to $i$ ) find combinations of the adsorption parameters $A_{\mathrm{FHH}}, B_{\mathrm{FHH}}$ which yield atmospherically-relevant behavior, and, $i$ ) express activation properties (critical supersaturation) that follow a simple power law with respect to dry particle diameter.

The new parameterization is tested by comparing the parameterized cloud droplet number concentration against predictions with a detailed numerical cloud model, considering a wide range of particle populations, cloud updraft conditions, water vapor condensation coefficient and FHH adsorption isotherm characteristics. The agreement between parameterization and parcel model is excellent, with an average error
\end{abstract}

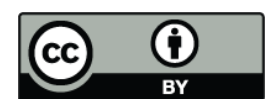

Correspondence to: A. Nenes (nenes@eas.gatech.edu) of $10 \%$ and $R^{2} \sim 0.98$. A preliminary sensitivity study suggests that the sublinear response of droplet number to Köhler particle concentration is not as strong for FHH particles.

\section{Introduction}

It is well established that atmospheric aerosols are often hydrophilic, and can serve as Cloud Condensation Nuclei $(\mathrm{CCN})$, upon which cloud droplets are formed through the process of activation. Changes in $\mathrm{CCN}$ concentration affect the radiative properties of clouds, known as the "cloud albedo" or "Twomey" effect of aerosols (Twomey, 1974). The enhanced number of droplets is often accompanied by a reduction in their size, thereby affecting cloud precipitation efficiency. This may result in increased cloudiness, which gives rise to the so-called "cloud lifetime" or "Albrecht" effect of aerosols (Albrecht, 1989). Combined, these "aerosol indirect effects" on clouds perturb the Earth's radiative budget and constitute one of the most uncertain components of anthropogenic climate change (Forster et al., IPCC, 2007).

Cloud droplet activation is the direct microphysical link between aerosols and clouds, and is at the heart of the indirect effect (Nenes and Seinfeld, 2003). Droplet activation in atmospheric models is calculated from parameterizations whose sophistication range from empirical correlations (relating aerosol mass or number concentration to cloud droplet number concentration) to physically-based prognostic formulations (e.g., Feingold and Heymsfield, 1992; Boucher and Lohmann, 1995; Gultepe and Isaac, 1996; Abdul-Razzak et al., 1998; Abdul-Razzak and Ghan, 2000; Cohard et al., 2000; Nenes and Seinfeld, 2003; Fountoukis and Nenes,

Published by Copernicus Publications on behalf of the European Geosciences Union. 
2005; Ming et al., 2006; Barahona and Nenes, 2007). All physically-based parameterizations developed to date rely on Köhler theory (Köhler, 1936), which considers curvature and solute effects on the equilibrium vapor pressure of a growing droplet. Most often, this equilibrium curve exhibits a maximum in supersaturation known as critical supersaturation, $s_{c}$, at a critical wet droplet diameter, $D_{c}$. When a particle is exposed to supersaturation above $s_{c}$ for long enough to exceed $D_{c}$, it is in unstable equilibrium and can nucleate a cloud droplet. For atmospherically-relevant conditions of cloud formation, it is sufficient to say that a particle acts as a $\mathrm{CCN}$ when is exposed to supersaturation above $s_{c}$ (Nenes et al., 2001).

Insoluble atmospheric particles, like mineral dust and soot, can also act as efficient cloud condensation nuclei if they acquire some amount of deliquescent material, such as $\left(\mathrm{NH}_{4}\right)_{2} \mathrm{SO}_{4}$ (e.g., Seisel et al., 2005). The threshold of nucleation substantially decreases when water interacts (adsorbs) onto slightly soluble particles giving rise to the process of adsorption activation (Sorjamaa and Laaksonen, 2007; Henson, 2007). Henson (2007) showed that a number of existing adsorption models (e.g., Fletcher, 1958; Wexler and Ge, 1998) for slightly soluble and insoluble particles can be successfully applied to represent droplet formation from adsorption activation. Similarly, Sorjamaa and Laaksonen (2007) used the Frenkel-Halsey-Hill (FHH) multilayer physical adsorption model to describe water uptake as a function of relative humidity (i.e., water activity) and applied the theory to describe the activation of perfectly wettable and insoluble hydrophilic CCN. As with Köhler theory, adsorption of water can result in equilibrium curves with a critical supersaturation of atmospheric relevance (Henson, 2007; Sorjamaa and Laaksonen, 2007).

To date, there is no parameterization framework that can concurrently treat the competition of insoluble and soluble $\mathrm{CCN}$ in the cloud droplet formation process; this gap is addressed in this study. The new activation parameterization builds upon the frameworks of Nenes and Seinfeld (2003), Fountoukis and Nenes (2005) and Barahona and Nenes (2007) to include the effects of adsorption activation, using the FHH theory of Sorjamaa and Laaksonen (2007). The insoluble particles (referred to in this study as "FHH particles") are considered to be externally mixed with hydrophilic deliquescent particles (referred to as "Köhler particles"). All particles compete for water vapor in a cloud updraft, thus allowing for the comprehensive treatment of kinetic limitations, chemical effects (i.e., slow water vapor condensation and surface tension depression) and entrainment effects on cloud droplet formation.

A brief discussion of FHH adsorption activation and Köhler theory is given in Sect. 2. Section 3 describes the formulation of the new parameterization for sectional and lognormal representation of the aerosol size distribution. An evaluation of the parameterization by comparing against predictions of a numerical cloud parcel model is done in Sect. 4.
Section 5 provides an insight into the competition effects of FHH with Köhler particles. Finally, Sect. 6 summarizes the major achievements of this study.

\section{Theory of adsorption activation}

A number of adsorption isotherm models exist to describe the process of physisorption of gas-phase species onto solid surfaces, such as Langmuir (Langmuir, 1916), BET (Brunauer, Emmett and Taylor) (Brunauer et al., 1938), and FHH (Frenkel, Halsey and Hill) (e.g., Lowell et al., 2004) isotherms. The Langmuir isotherm is the first and perhaps the most studied adsorption model to date, but is limited to the adsorption of a monolayer of water vapor, and hence it is not applicable to atmospheric particle (where the vapor pressure is high enough to form multiple layers of water vapor adsorbed onto the $\mathrm{CCN}$ ). BET and FHH were developed to treat multilayer adsorption, and have been explored to study adsorption activation, or, the process of cloud droplet formation from adsorption of water vapor onto insoluble particles (e.g., Henson, 2007; Sorjamaa and Laaksonen, 2007).

\subsection{FHH adsorption theory}

FHH adsorption theory (Sorjamaa and Laaksonen, 2007) describes the process of adsorption activation in which the water vapor saturation ratio, $S$, of an insoluble particle in equilibrium with surrounding water vapor can be expressed as

$S=\alpha_{w} \exp \left(\frac{4 \sigma M_{w}}{R T \rho_{w} D_{p}}\right)$

where $\alpha_{w}$ is the activity of the water in the particle, $\sigma$ is the surface tension at the particle-gas interface, $M_{w}$ is the molar mass of water, $R$ is the universal gas constant, $T$ is the temperature, $\rho_{w}$ is the density of water, and $D_{p}$ is the equivalent particle diameter. The exponential in Eq. (1) is commonly referred to as the curvature, or Kelvin effect. For irregularly shaped insoluble particles (such as dust), curvature along its surface varies, and cannot be described in terms of a single characteristic diameter. In this study, we consider only the average curvature, as expressed by the equivalent particle diameter. Furthermore, the insoluble particle surface is assumed to be perfectly wettable (i.e., the contact angle between the particle and water is zero), resulting in a uniform distribution of adsorbed water molecules over the particle surface. In the limit of a monolayer, its activity, $\alpha_{w}$, can be written as $\alpha_{w}=\exp \left(-A_{\mathrm{FHH}} \Theta^{-B_{\mathrm{FHH}}}\right.$ ) (Sorjamaa and Laaksonen, 2007); substitution in Eq. (1) then gives

$S=\exp \left(\frac{4 \sigma M_{w}}{R T \rho_{w} D_{p}}\right) \exp \left(-A_{\mathrm{FHH}} \Theta^{-B_{\mathrm{FHH}}}\right)$

where $A_{\mathrm{FHH}}, B_{\mathrm{FHH}}$ are empirical constants, and $\Theta$ is the surface coverage (defined as the number of adsorbed water molecules divided by the number of molecules in a monolayer, i.e., the number of adsorbed layers of water). $A_{\mathrm{FHH}}$ 
characterizes interactions of adsorbed molecules with the aerosol surface and adjacent adsorbate molecules (i.e., those in the first monolayer). $B_{\mathrm{FHH}}$ characterizes the attraction between the aerosol surface and the adsorbate in subsequent layers; the smaller the value of $B_{\mathrm{FHH}}$, the greater the distance at which the attractive forces act (Sorjamaa and Laaksonen, 2007). $A_{\mathrm{FHH}}$ and $B_{\mathrm{FHH}}$ are compound-specific and determined experimentally. $A_{\mathrm{FHH}}$ has been experimentally found to range from 0.1 to 3.0 , while, $B_{\mathrm{FHH}}$ ranges from 0.5 to 3.0 (Sorjamaa and Laaksonen, 2007).

Equation (2) expresses $S$ in terms of $D_{p}$ and $\Theta$. However, $\Theta$ can be expressed in terms of $D_{\text {dry }}$ and $D_{p}$ as (Sorjamaa and Laaksonen, 2007):

$\Theta=\frac{D_{p}-D_{\text {dry }}}{2 D_{w}}$

where $D_{\text {dry }}$ is the dry particle diameter and $D_{w}=2.75 \AA$ is the diameter of a water molecule adsorbed on the particle surface. Substituting Eq. (3) into Eq. (2), expressed in terms of equilibrium supersaturation $s=S-1$, gives an equation that depends only on $D_{p}$,

$$
\begin{aligned}
s & =\exp \left[\frac{4 \sigma M_{w}}{R T \rho_{w} D_{p}}-A_{\mathrm{FHH}}\left(\frac{D_{p}-D_{\mathrm{dry}}}{2 D_{w}}\right)^{-B_{\mathrm{FHH}}}\right]-1 \\
& \cong \frac{4 \sigma M_{w}}{R T \rho_{w} D_{p}}-A_{\mathrm{FHH}}\left(\frac{D_{p}-D_{\mathrm{dry}}}{2 D_{w}}\right)^{-B_{\mathrm{FHH}}}
\end{aligned}
$$

The activation behavior of particles following FHH theory can be rationalized by analyzing the derivative of $s$ with respect to $D_{p}$ :

$$
\frac{d s}{d D_{p}}=\left(-\frac{4 \sigma M_{w}}{R T \rho_{w} D_{p}^{2}}\right)+\left(\frac{A_{\mathrm{FHH}} B_{\mathrm{FHH}}}{2 D_{w}}\left(\frac{D_{p}-D_{\mathrm{dry}}}{2 D_{w}}\right)^{-B_{\mathrm{FHH}}-1}\right)
$$

where the first and second terms in the right hand side of Eq. (5) correspond to the contribution from the Kelvin and adsorption effect, respectively. If $B_{\mathrm{FHH}}$ is large enough, both terms in Eq. (5) can become equal for a characteristic wet diameter, $D_{c}$, so that $\left.\frac{d s}{d D_{p}}\right|_{D_{p}=D_{c}}=0$. Under such conditions, FHH particles behave much like those following Köhler theory, with a characteristic maximum $s$ (the critical supersaturation, $s_{c}$ ) at the critical wet diameter $D_{c} . s_{c}$ is determined by solving $\frac{d s}{d D_{p}}=0$, so Eq. (5) becomes

$$
\left(-\frac{4 \sigma M_{w}}{R T \rho_{w} D_{c}^{2}}\right)+\left(\frac{A_{\mathrm{FHH}} B_{\mathrm{FHH}}}{2 D_{w}}\left(\frac{D_{c}-D_{\mathrm{dry}}}{2 D_{w}}\right)^{-B_{\mathrm{FHH}}-1}\right)=0
$$

Numerically solving Eq. (6) gives $D_{c}$, which can then be substituted in Eq. (4) to obtain $s_{c}$. Figure 1a presents equilibrium curves for combinations of $A_{\mathrm{FHH}}, B_{\mathrm{FHH}}$ that exhibit a maximum $s_{c}$ and its corresponding $D_{c}$.
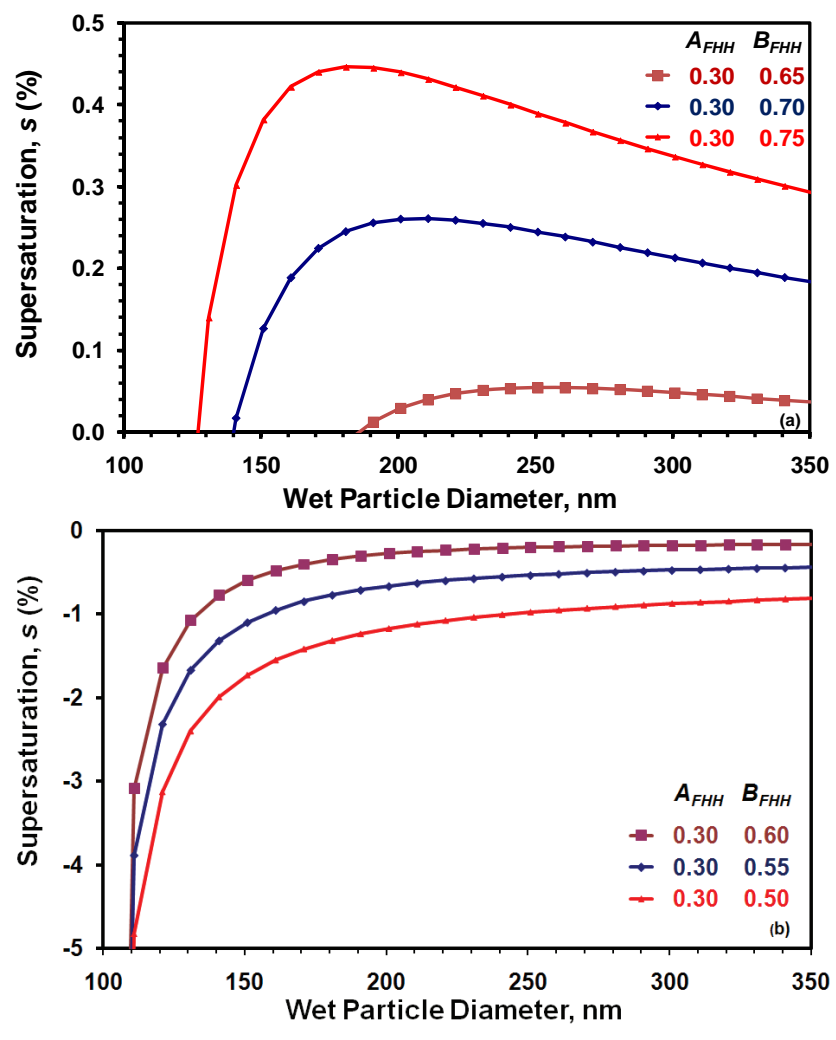

Fig. 1. Equilibrium curves for a FHH-type particle of $100 \mathrm{~nm}$ dry diameter, and combinations of $A_{\mathrm{FHH}}, B_{\mathrm{FHH}}$ that represent (a) atmospherically-relevant behavior, and, (b) spontaneous activation (for $\mathrm{RH}<100 \%$ ).

If $B_{\mathrm{FHH}}$ is small enough so that the left hand side of Eq. (6) is larger than zero for all values of $D_{p}$, then the derivative of the equilibrium curve is dominated by the adsorption term and the particle either (a) is always in stable equilibrium with the environment, i.e., the particles never activate into cloud droplets, or, (b) spontaneously activate at RH less than $100 \%$ (depending on the asymptotic value of $s$ at very large $D_{p}$ ). Figure $1 \mathrm{~b}$ presents examples of such curves, the equilibrium supersaturation does not exhibit a maximum, but rather asymptotes to a value, $s_{\infty}$, less than zero. If the ambient relative humidity is such that $s<s_{\infty}$, the particle is always in stable equilibrium with the environment. Conversely, if $s>s_{\infty}$, the particle spontaneously activates into a cloud droplet (even for a relative humidity less than 100\%). Such phenomena (i.e. deliquescent clays) have not been observed hence this region of parameter space is considered irrelevant for the atmosphere.

\subsection{Activation characteristics of Köhler and FHH par- ticles}

The activation of particles containing soluble material is described by Köhler theory (Köhler, 1936; Seinfeld and Pandis, 
2006) in which equilibrium supersaturation is given by

$s=\frac{A}{D_{p}}-\frac{B}{D_{p}^{3}}$

where $A=\frac{4 M_{w} \sigma}{R T \rho_{w}}$ and $B=\frac{6 n_{s} M_{w} v}{\pi \rho_{w}}$. Here $n_{s}$ is the number moles of solute in the particle and $v$ is the effective van't Hoff factor of the solute. The $s_{c}$ and $D_{c}$ for Köhler particles are then given by:

$s_{c}=\left(\frac{4 A^{3}}{27 B}\right)^{1 / 2}$

$D_{c}=\left(\frac{3 B}{A}\right)^{1 / 2}$

The above analytical expressions for $s_{c}$ and $D_{c}$ neglect the insoluble $\mathrm{CCN}$ fraction in the denominator of the second term on the right hand side of Eq. (7), also known as "Raoult" term and should not be used for particles with very small soluble fractions (e.g., Khvorostyanov and Curry, 2007).

For FHH particles, it is important to know the range of $A_{\mathrm{FHH}}$ and $B_{\mathrm{FHH}}$ which give equilibrium curves with a maximum (like in Fig. 1a) and therefore are potentially relevant for the atmosphere. This is done by determining values of $A_{\mathrm{FHH}}, \mathrm{B}_{\mathrm{FHH}}$ and $D_{\text {dry }}$ for which a solution to Eq. (6) exists, over the reported range for $A_{\mathrm{FHH}}$ and $B_{\mathrm{FHH}}(0.1-3.0$ and $0.5-$ 3.0, respectively) $D_{\text {dry }}$ is also varied between $0.03 \mu \mathrm{m}$ and $150 \mu \mathrm{m}$. When a solution for $D_{c}$ is found, we normalize it with $D_{\text {dry }}$ to express the growth required for FHH particles to activate into cloud droplets.

Figure 2 shows contour plots of $D_{c} / D_{\text {dry }}$ for $D_{\text {dry }}$ equal to $0.25 \mu \mathrm{m}$ and $20 \mu \mathrm{m}$. Depending on the existence and value of $D_{c} / D_{\mathrm{dry}}$, each plot of Fig. 2 can be divided into three separate regions: "Region 1" (area filled with purple color, corresponding to $B_{\mathrm{FHH}}<0.6-0.7$ for any value of $A_{\mathrm{FHH}}$ ), where equilibrium curves are like in Fig. $1 \mathrm{~b}$ and a $D_{c}$ could not be found. "Region 2" (corresponding to $0.7<B_{\mathrm{FHH}}<1.0$ ), where equilibrium curves resemble those of Fig. 1a, for $D_{c} / D_{\text {dry }}>2$. Finally, "Region 3" (area filled with red color, corresponding to $B_{\mathrm{FHH}}>1.0$ ), where equilibrium curves resemble those in Fig. 1a, and $D_{c} / D_{\text {dry }}<2$. Figure 2a and b, are very similar, despite that they correspond to particles with two orders of magnitude differences in dry particle sizes. This suggests that $D_{c} / D_{\text {dry }}$ has a weak dependence on $D_{\text {dry }}$. Furthermore, most of the atmospherically-relevant combinations of $A_{\mathrm{FHH}}$ and $B_{\mathrm{FHH}}$ lie in "Region 3", where the value of $D_{c} / D_{\text {dry }}$ lies between $1-2$. Given that the size of activated droplets at the cloud parcel $s_{\max }$ are typically much larger than $D_{\text {dry }}$ (Nenes and Seinfeld, 2003), it can be assumed that $D_{p} \gg D_{c}$ for FHH particles at $s_{\max }$. This is an important observation that facilitates the computation of the condensation rate of water, required in the development of the droplet activation parameterization (Sect. 3.6). Another implication is that the amount of water required to activate FHH particles
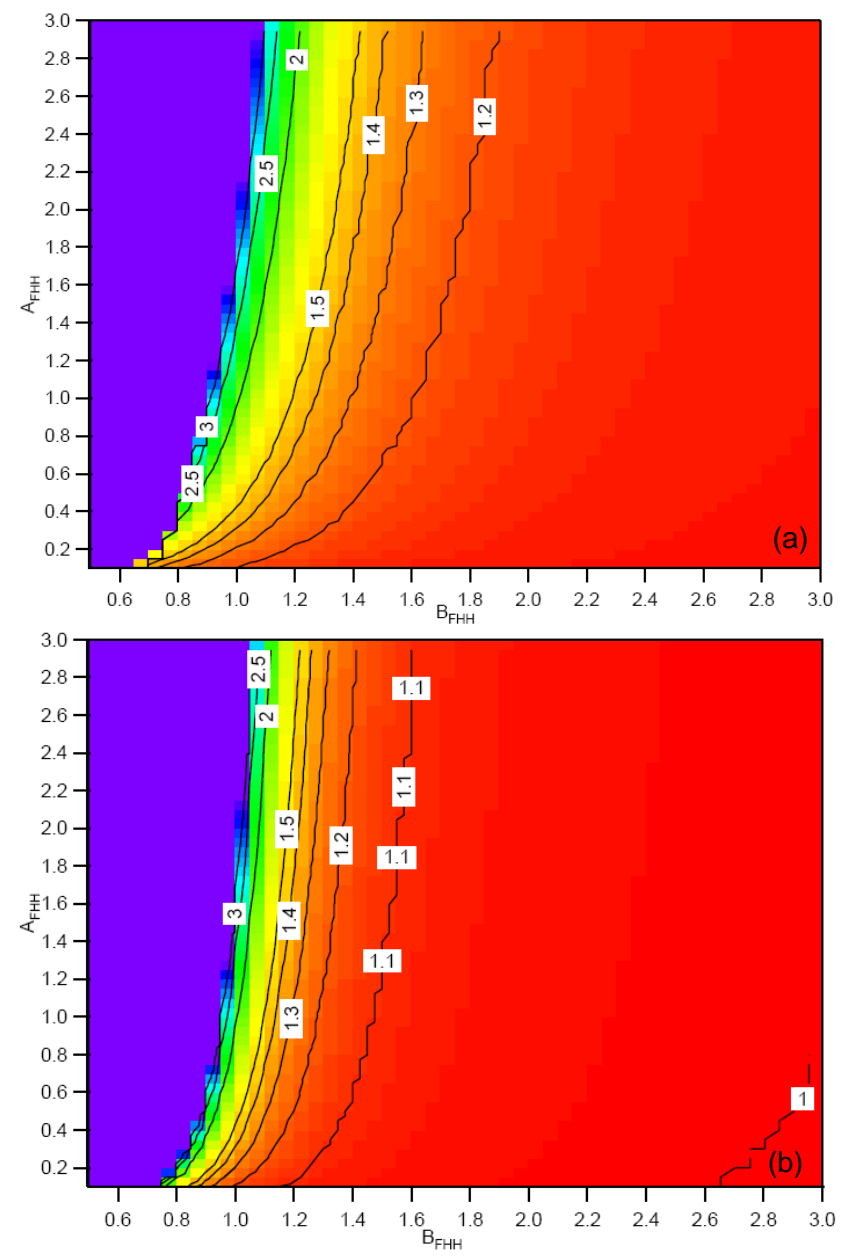

Fig. 2. $D_{c} / D_{\text {dry }}$ contours as a function of $A_{\mathrm{FHH}}$ and $B_{\mathrm{FHH}}$ for (a) $D_{\text {dry }}=0.25 \mu \mathrm{m}$, and (b) $D_{\text {dry }}=20 \mu \mathrm{m}$.

is often much smaller than for Köhler particles of same $D_{\text {dry }}$ (Table 1), or same $s_{c}$ (not shown).

The most appropriate activation theory for a particle depends on the relative importance of adsorption vs. solute on water activity. The theory that gives the lowest $s_{c}$ will, in general, be the most appropriate. A quantitative evaluation requires an extensive set of simulations and will be the focus of a future study.

\section{Formulation of activation parameterization}

The aerosol activation parameterization is based on the cloud parcel framework, in which a parcel of air containing an external mixture of Köhler and FHH particles is lifted and cooled. When supersaturation develops, droplets begin to form (by the process of activation) up to the point where supersaturation generation from cooling balances depletion from condensation of water; this corresponds to the point of 
Table 1. Comparison of critical to dry particle diameter for $\mathrm{FHH}$ and Köhler particles composed of pure $\left(\mathrm{NH}_{4}\right)_{2} \mathrm{SO}_{4}$.

\begin{tabular}{ccc}
\hline$D_{\text {dry }}(\mu \mathrm{m})$ & $\left(D_{c} / D_{\text {dry }}\right)_{\mathrm{FHH}^{\mathrm{a}}}$ & $\left(D_{c} / D_{\mathrm{dry}}\right)_{\text {Köhler }^{\mathrm{b}}}$ \\
\hline 0.01 & 1.81 & 3.13 \\
0.025 & 1.86 & 4.80 \\
0.05 & 1.91 & 7.00 \\
0.075 & 1.93 & 8.53 \\
1.00 & 2.13 & 31.31 \\
2.50 & 2.23 & 49.48 \\
5.00 & 2.30 & 70.01 \\
7.50 & 2.32 & 85.75 \\
10.00 & 2.38 & 99.02 \\
15.00 & 2.44 & 121.27 \\
20.00 & 2.48 & 140.03 \\
\hline
\end{tabular}

${ }^{\text {a }} D_{c}$ calculated from Eq. (6),

$A_{\mathrm{FHH}}=0.68, B_{\mathrm{FHH}}=0.93, D_{w}=2.75 \AA$

b $D_{c}$ calculated from Eq. (8b), $\nu=3, \sigma=0.72 \mathrm{~N} \mathrm{~m}^{-1}$,

$M_{w}=18.0 \mathrm{~g} \mathrm{~mol}^{-1}, M_{\left(\mathrm{NH}_{4}\right)_{2} \mathrm{SO}_{4}}=132.14 \mathrm{~g} \mathrm{~mol}^{-1}$,

$\rho_{w}=1000 \mathrm{~kg} \mathrm{~m}^{-3}$

maximum parcel supersaturation, $s_{\max }$, and is where droplet activation ceases. If the $\mathrm{CCN}$ spectrum (i.e., the number of $\mathrm{CCN}$ as a function of ambient supersaturation) and $s_{\max }$ are known, the droplet number, $N_{d}$, in the parcel can be computed as the number of $\mathrm{CCN}$ that activate at $s_{\max }$ (Nenes et al., 2001). The new parameterization provides a formulation to determine both $s_{\max }$ and $N_{d}$. Since sectional and lognormal representations of the aerosol particle size distribution are most frequently used in the models, formulations are developed for both.

\subsection{Sectional representation of CCN spectrum}

The sectional representation uses discrete size classes ("bins" or "sections") for the aerosol distribution. Each section can have its own chemical composition. If the aerosol mixture is composed of $k$ populations (i.e., aerosol types), then a separate binning is assigned to each type. The cumulative size distribution is then determined by summing over all the populations (Nenes and Seinfeld, 2003):

$$
\begin{aligned}
F^{d}(d) & =\sum_{l=1}^{k} \int_{0}^{d} n_{l}^{d}\left(D_{p}^{\prime}\right) d\left(D_{p}^{\prime}\right) \\
& =\sum_{l=1}^{k}\left[\sum_{j=1}^{m(l)-1} N_{j, l}+N_{m(l), l}\left(\frac{d-D_{p, m(l)-1}^{l}}{D_{p, m(l)}^{l}-D_{p, m(l)-1}^{l}}\right)\right]
\end{aligned}
$$

where $m$ is the section of population $l$ that contains particles of size $d$ with bin size limits $D_{p, m(l)-1}^{l}$ and $D_{p, m(l)}^{l}$, and $N_{m(l), l}$ is the aerosol number concentration of section $m$.

The aerosol critical supersaturation distribution function, $n_{l}^{s}(s)$, is then determined by mapping the aerosol particle size distribution onto supersaturation coordinates (Nenes and Seinfeld, 2003),

$n_{l}^{s}(s)=\frac{d N}{d s}=\sum_{l=1}^{k} \frac{N_{i(l), l}}{s_{c, i(l)}-s_{c, i(l)-1}}, \quad s_{c, i(l)-1} \leq s \leq s_{c, i(l)}$

where $s_{c, i(l)}$ and $s_{c, i(l)-1}$ are the critical supersaturations corresponding to the boundaries of section $i$ and population $l$, and $N_{i(l), l}$ is the concentration of $\mathrm{CCN}$ between $s_{c, i(l)}$ and $s_{c, i(l)-1}$. The CCN spectrum, $F^{s}(s)$, is then obtained by integration of $n^{s}\left(s^{\prime}\right)$ from $s^{\prime}=0$ to $s^{\prime}=s$ :

$$
\begin{aligned}
F^{s}(s) & =\sum_{l=1}^{k} \int_{0}^{s} n_{l}^{s}\left(s^{\prime}\right) d s^{\prime} \\
& =\sum_{l=1}^{k}\left[\sum_{j=1}^{i(l)-1} N_{j, l}+N_{i(l), l}\left(\frac{s-s_{c, i(l)-1}^{l}}{s_{c, i(l)}^{l}-s_{c, i(l)-1}^{l}}\right)\right]
\end{aligned}
$$

The relationship between $s_{c, i(l)}^{l}$ and $D_{p, m(l)}^{l}$ depends on the theory used for describing activation. For Köhler particles, Eq. (8a) and (b) is used, while for FHH particles, the procedure outlined in Sect. 2.1 is used.

\subsection{Lognormal representation of $\mathrm{CCN}$ spectrum}

A lognormal distribution is often expressed as sum of several lognormal functions (or "modes"):

$$
\frac{d N}{d \ln D_{\mathrm{dry}}}=\sum_{i=1}^{n_{m}} \frac{N_{i}}{\sqrt{2 \pi} \ln \sigma_{i}} \exp \left[-\frac{\ln ^{2}\left(D_{\mathrm{dry}} / D_{g, i}\right)}{2 \ln ^{2} \sigma_{i}}\right]
$$

where $\sigma_{i}$ and $D_{g, i}$ are the geometric standard deviation and median diameter, respectively, for the $i^{\text {th }}$ lognormal mode, and $n_{m}$ is the number of lognormal modes in the size distribution. Assuming each mode (or population) has uniform chemical composition, a power law function can be used to express $D_{\text {dry }} / D_{g, i}$ in terms of a critical supersaturation ratio, $s / s_{g, i}$

$\frac{D_{\text {dry }}}{D_{g, i}}=\left[\frac{s}{s_{g, i}}\right]^{\frac{1}{x}}$

where $s$ and $s_{g, i}$ are critical supersaturations of $\mathrm{CCN}$ with dry diameter $D_{\text {dry }}$ and $D_{g, i}$ respectively, and $x$ is an exponent that depends on the activation theory used. For particles following Köhler theory, $x=-3 / 2$ (Fountoukis and Nenes, 2005), while for FHH particles, $x$ depends on $A_{\mathrm{FHH}}$ and $B_{\text {FHH }}$ (see Sect. 3.3).

The aerosol critical supersaturation distribution function, $n^{s}(s)$, can then be calculated as follows (Fountoukis and Nenes, 2005)

$n^{s}(s)=\frac{d N}{d s}=-\frac{d N}{d \ln D_{\mathrm{dry}}} \frac{d \ln D_{\mathrm{dry}}}{d s}$ 
where the negative sign in the right hand side of Eq. (14) has been applied to reflect that $s_{c}$ decreases as $D_{\text {dry }}$ increases. Implicit is the division of $D_{\text {dry }}$ with $1 \mu \mathrm{m}$ to nondimensionalize the argument in $\ln D_{\text {dry }}$. Substituting $D_{\text {dry }} / D_{g, i}$ from Eq. (13) into Eq. (12) gives

$\frac{d N}{d \ln D_{\mathrm{dry}}}=\sum_{i=1}^{n_{m}} \frac{N_{i}}{\sqrt{2 \pi} \ln \sigma_{i}} \exp \left[-\frac{\ln ^{2}\left(s / s_{g, i}\right)^{\frac{1}{x}}}{2 \ln ^{2} \sigma_{i}}\right]$

Differentiating Eq. (13) also gives

$\frac{d \ln D_{\mathrm{dry}}}{d s}=\frac{1}{x s}$

Substituting Eq. (15) and Eq. (16) into Eq. (14) gives

$n^{s}(s)=\sum_{i=1}^{n_{m}}-\frac{N_{i}}{\sqrt{2 \pi} \ln \sigma_{i}} \frac{1}{x s} \exp \left[-\frac{\ln ^{2}\left(s / s_{g, i}\right)^{\frac{1}{x}}}{2 \ln ^{2} \sigma_{i}}\right]$

The CCN spectrum, $F^{s}(s)$ is then obtained by integration of $n^{s}\left(s^{\prime}\right)$ from $s^{\prime}=0$ to $s^{\prime}=s$ :

$F^{s}(s)=\int_{0}^{s} n^{s}\left(s^{\prime}\right) d s^{\prime}=\sum_{i=1}^{n_{m}} \frac{N_{i}}{2} \operatorname{erfc}\left[-\frac{\ln \left(s_{g, i} / s\right)}{x \sqrt{2} \ln \sigma_{i}}\right]$

Equation (18) is the generalized form of a $\mathrm{CCN}$ spectrum for the lognormal particle size distribution, and the value of $x$ encompasses the physics behind the aerosol-water vapor interaction (i.e., Köhler or FHH). For $x=-3 / 2$ (Köhler particles), Eq. (18) reduces to the formulation given by Fountoukis and Nenes, (2005):

$F^{s}(s)=\int_{0}^{s} n^{s}\left(s^{\prime}\right) d s^{\prime}=\sum_{i=1}^{n_{m}} \frac{N_{i}}{2} \operatorname{erfc}\left[\frac{2 \ln \left(s_{g, i} / s\right)}{3 \sqrt{2} \ln \sigma_{i}}\right]$

\subsection{Relating $s_{c}$ with $D_{\text {dry }}$ for FHH particles}

In determining the value of $x$ in Eq. (13) for FHH particles, we computed numerically the ratio of $s / s_{g, i}$ (using the procedure in Sect. 2.1) for a wide range of $D_{g, i}(0.03 \mu \mathrm{m}-10 \mu \mathrm{m})$, $D_{\text {dry }}(0.05 \mu \mathrm{m}-0.8 \mu \mathrm{m}), A_{\mathrm{FHH}}$ and $B_{\mathrm{FHH}}(10$ different combinations as shown in Table 2). As can be seen in Fig. 3, for given values of $A_{\mathrm{FHH}}$ and $B_{\mathrm{FHH}}, s / s_{g, i}$ and $D_{\mathrm{dry}} / D_{g, i}$, exhibit a power-law dependence. This dependence holds for the entire range of $D_{g, i}$ and $D_{\text {dry }}$ considered. Power law fits to these calculations can then be used to describe $x$ as a function of $A_{\mathrm{FHH}}$ and $B_{\mathrm{FHH}}$, some results of which are shown in Fig. 4. For each $A_{\mathrm{FHH}}, x$ has a maximum at $B_{\mathrm{FHH}} \sim 1.3-1.4$, while $x$ is always negative, varying from -1.2 to -0.8 , depending on the value of $A_{\mathrm{FHH}}$.

Multivariate least squares regression was performed on the activation data for all the conditions in Table 2 to determine an analytical relationship between $x, A_{\mathrm{FHH}}$ and $B_{\mathrm{FHH}}$ :

$x=A_{\mathrm{FHH}}^{P_{1}}\left[\frac{P_{2}}{B_{\mathrm{FHH}}^{P_{3}}}-\frac{P_{4}}{B_{\mathrm{FHH}}^{P_{5}}}\right]$
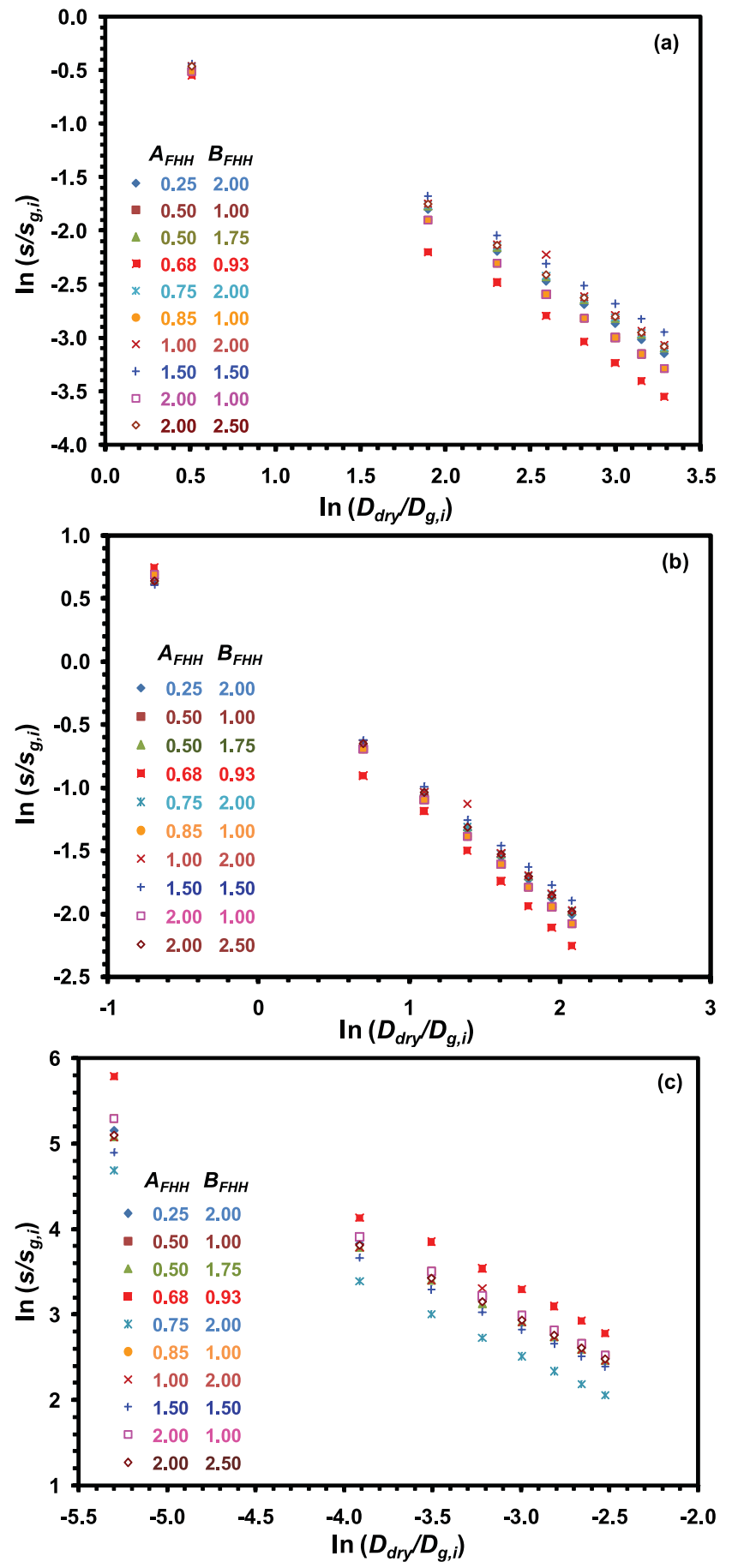

Fig. 3. Plot of $\ln \left(s / s_{g, i}\right)$ versus $\ln \left(D_{\text {dry }} / D_{g, i}\right)$ for (a) $D_{g, i}=0.03 \mu \mathrm{m}$, (b) $D_{g, i}=0.1 \mu \mathrm{m}$ and (c) $D_{g, i}=10.0 \mu \mathrm{m}$.

where $P_{1}, P_{2}, P_{3}, P_{4}, P_{5}$ are fitting parameters, and are given in Table 3. Equation (20) reproduces the fitted $x$ data with a root mean square error of 0.00996 (Fig. 4).

Equation (13) suggests that $s_{c}$ of FHH particles can be written as $s_{C}=C D_{\mathrm{dry}}^{x} ; C$ is a constant that depends on $A_{\mathrm{FHH}}$ 
Table 2. Cloud formation conditions considered in this study.

\begin{tabular}{ll}
\hline Property & Values \\
\hline$\alpha_{c}$ & $0.042,0.06,1.0$ \\
$V\left(\mathrm{~m} \mathrm{~s}^{-1}\right)$ & $0.1,0.5,1.0,5.0,10.0$ \\
$T_{\text {parcel }}(\mathrm{K})$ & 298 \\
$P_{\text {parcel }}(\mathrm{mbar})$ & 900 \\
$\left(A_{\mathrm{FHH}}, B_{\mathrm{FHH}}\right)$ combinations considered for FHH particles & $(0.25,2.00),(0.50,1.00),(0.50,1.75),(0.68,0.93),(0.75,2.00)$, \\
& $(0.85,1.00),(1.00,2.00),(1.50,1.50),(2.00,1.00),(2.00,2.50)$ \\
Soluble Fraction properties & Species considered: $\left(\mathrm{NH}_{4}\right)_{2} \mathrm{SO}_{4}$ \\
& Soluble Mass Fraction, $\varepsilon: 0.5$ \\
& Density, $\rho: 1760 \mathrm{~kg} \mathrm{~m}^{-3}$ \\
& van't Hoff Factor, $v: 3$ \\
& Molar Mass: $0.132 \mathrm{~kg} \mathrm{~mol}^{-1}$ \\
\hline
\end{tabular}

Table 3. Fitting parameters in Eq. (20).

\begin{tabular}{lrrrll}
\hline$A_{\mathrm{FHH}}$ & $P_{1}$ & $P_{2}$ & $P_{3}$ & $P_{4}$ & $P_{5}$ \\
\hline$A_{\mathrm{FHH}} \leq 0.5$ & -0.01061 & -0.101038 & 4.6382 & 0.89161 & -0.05708 \\
$0.5<A_{\mathrm{FHH}} \leq 1.5$ & -0.02848 & -0.124812 & 9.4907 & 0.87878 & -0.06849 \\
$1.5<A_{\mathrm{FHH}}$ & -0.05994 & -0.185129 & 16.2757 & 0.86681 & -0.11858 \\
\hline
\end{tabular}

Table 4. Fitting parameters in Eq. (21).

\begin{tabular}{llllll}
\hline$A_{\mathrm{FHH}}$ & $k$ & $l$ & $m$ & $n$ & $p$ \\
\hline$A_{\mathrm{FHH}} \leq 0.5$ & 0.211 & 4.038 & 0.849 & 4.156 & 19.835 \\
$0.5<A_{\mathrm{FHH}} \leq 1.5$ & 0.398 & 6.706 & 0.994 & 7.039 & 19.742 \\
$1.5<A_{\mathrm{FHH}}$ & 0.656 & 8.270 & 1.364 & 8.739 & 19.705 \\
\hline
\end{tabular}

and $B_{\mathrm{FHH}}$ and is numerically equal to the critical supersaturation of a particle of a reference dry diameter. In this study, the reference diameter is taken to be $0.1 \mu \mathrm{m} ; C$ is then determined by computing $s_{C}$ (Sect. 2.1) over a range of $A_{\mathrm{FHH}}$ and $B_{\mathrm{FHH}}$. This is presented in Fig. 5 where $C$ (shown as symbols) are plotted together with a multivariate least squares regression to the following function (shown as lines):

$C=10^{-8} A_{\mathrm{FHH}}^{k}\left[\frac{-21}{B_{\mathrm{FHH}}^{l}}+\frac{1.3}{B_{\mathrm{FHH}}^{m}}+\frac{p}{B_{\mathrm{FHH}}^{n}}\right]$

where $C$ is expressed in $\mu \mathrm{m}^{-x}$, and $k, l, m, n, p$ are fitting constants given in Table 4. Equation (21) reproduces the fitted data with a root mean square error of 0.034 (Fig. 5).

\subsection{Computation of $s_{\max }$ and $N_{d}$}

The $s_{\max }$ in a cloud corresponds to the point where droplet activation terminates, and, occurs where supersaturation generation from cooling balances depletion from condensation

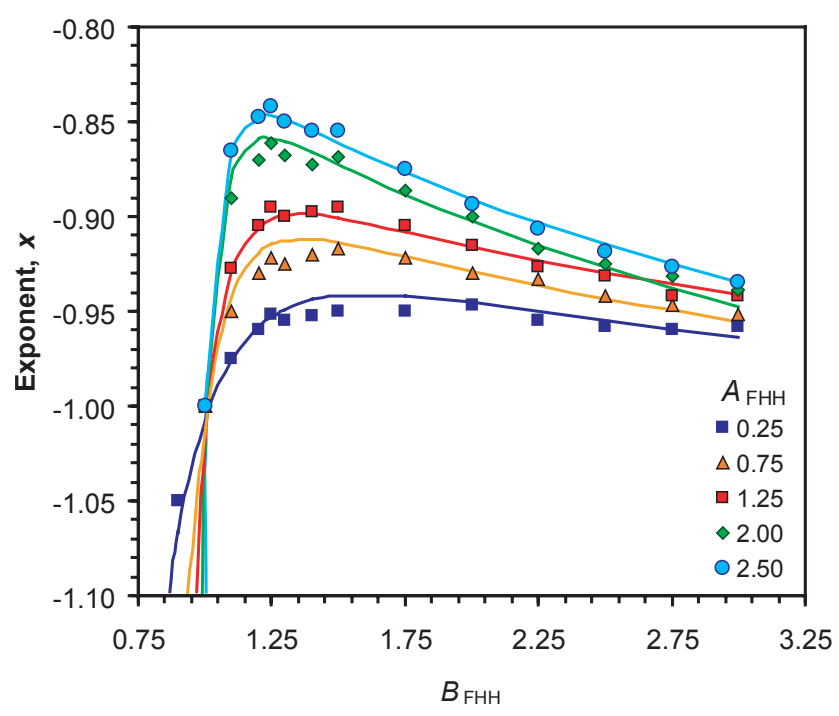

Fig. 4. Exponent $x$ for FHH particles as a function of $B_{\mathrm{FHH}}$ for different values of $A_{\mathrm{FHH}}$. Shown are values computed using the procedure of Sect. 2.1 (symbols) and the functional fit (line), given by Eq. (20).

of water vapor. For a non-adiabatic (entraining) cloud parcel ascending with constant velocity $V, s_{\max }$ can be determined from the solution of the following equation (Barahona and Nenes, 2007)

$$
\frac{2 \alpha V \rho_{a}}{\pi \gamma \rho_{w}}-G s_{\max } \int_{0}^{s_{\max }}\left(D_{p}^{2}(\tau)+2 G \int_{\tau}^{t_{\max }} s d t\right)^{1 / 2} n^{s}\left(s^{\prime}\right) d s^{\prime}=0
$$




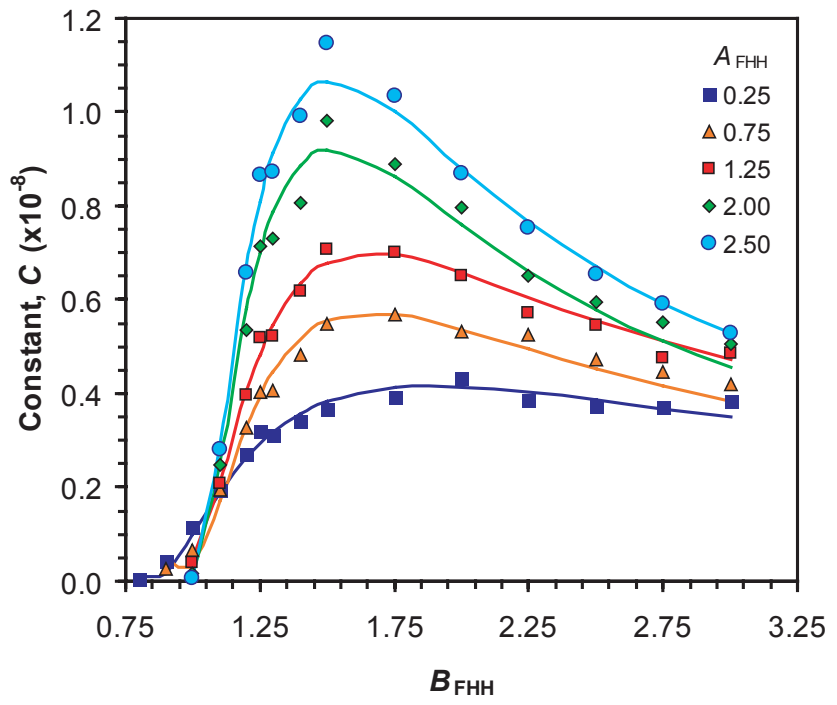

Fig. 5. Constant $C\left(\mu \mathrm{m}^{-x}\right)$, which relates $s_{C}$ of FHH particles to $D_{\text {dry }}$ as $s_{C}=C D_{\text {dry }}^{x} . C$ is presented for the atmospherically-relevant range of $B_{\mathrm{FHH}}$ and $A_{\mathrm{FHH}}$; shown are calculations using the procedure of Sect. 3.3 (symbols) and the functional fit (line), given by Eq. (21).

where $D_{p}(\tau)$ is the size of $\mathrm{CCN}$ when exposed to $s=s_{c}$ ( $\tau$ being the time where the parcel supersaturation exceeds the CCN critical supersaturation), $\gamma=\frac{p M_{a}}{p^{s} M_{w}}+\frac{M_{w} \Delta H_{v}^{2}}{c_{p} R T^{2}}$, $\alpha=\frac{g M_{w} \Delta H_{v}}{c_{p} R T^{2}}-\frac{g M_{a}}{R T}+e\left[\frac{\Delta H_{v} M_{w}}{R T^{2}}\left(T-T^{\prime}\right)-(1-\mathrm{RH})\right], \Delta H_{v}$ is the latent heat of condensation of water, $g$ is the acceleration due to gravity, $T$ is the temperature of the parcel, $M_{w}$ is the molar mass of water, $M_{a}$ is the molar mass of air, $c_{p}$ is the heat capacity of air, $p^{s}$ is the water saturation vapor pressure, $p$ is the ambient pressure, $e$ is the fractional entrainment from dry air into the parcel $\left(\mathrm{m}^{-1}\right)$, and $T^{\prime}$ and $\mathrm{RH}$ are the ambient temperature and fractional relative humidity, respectively and $R$ is the universal gas constant. $G$ in Eq. (22) is given by

$$
G=\frac{4}{\frac{\rho_{w} R T}{p^{s} D_{v}^{\prime} M_{w}}+\frac{\Delta H \rho_{w}}{k_{a} T}\left(\frac{\Delta H_{v} M_{w}}{R T}-1\right)}
$$

where $k_{a}$ is the thermal conductivity of air, and $D_{v}^{\prime}$ is the water vapor mass transfer coefficient from the gas to droplet phase corrected for non-continuum effects (calculated as discussed in Sect. 3.5). For an adiabatically rising parcel, $e=0$. Eq. (22) is written as,

$$
\frac{2 \alpha V \rho_{a}}{\pi \gamma \rho_{w}}-I_{e}\left(0, s_{\max }\right)=0
$$

where $I_{e}\left(0, s_{\max }\right)$ is the "condensation integral", given by

$I_{e}\left(0, s_{\max }\right)=G s_{\max } \int_{0}^{s_{\max }}\left(D_{p}^{2}(\tau)+2 G \int_{\tau}^{t_{\max }} \mathrm{sdt}\right)^{1 / 2} n^{s}\left(s^{\prime}\right) d s^{\prime}$
Calculation of $I_{e}\left(0, s_{\max }\right)$ is detailed in Sect. 3.6, which is then substituted in Eq. (24) and subsequently solved for $s_{\max }$. The number of cloud droplets that form in the parcel is

$N_{d}=F^{s}\left(s_{\max }\right)$

\subsection{The water vapor mass transfer coefficient}

It is well known that the mass transfer coefficient of water vapor onto droplets (otherwise known as the effective diffusivity), $D_{v}^{\prime}$, varies with particle size (Fukuta and Walter, 1970),

$D_{v}^{\prime}=\frac{D_{v}}{1+\frac{2 D_{v}}{\alpha_{c} D_{p}} \sqrt{\frac{2 \pi M_{w}}{R T}}}$

where $D_{v}$ is the water vapor diffusivity in air, and $\alpha_{c}$ is the water vapor uptake coefficient. The $\alpha_{c}$ is a kinetic parameter, expressing the probability of water vapor molecules of being incorporated into droplet upon collision. However, processes other than accommodation can control the condensation of water vapor (e.g., dissolution kinetics, Asa-Awuku and Nenes, 2007); $\alpha_{c}$ can thus be used to parameterize all processes affecting water mass transfer. Neglecting to account for the size dependency in $D_{v}^{\prime}$ results in overestimating water vapor condensation in the initial stages of cloud formation (Feingold and Chuang, 2002; Nenes et al.,2001; Fountoukis and Nenes, 2005; Ming et al., 2006), which can lead to an underestimation of $s_{\max }$ and $N_{d}$.

An analytical form of the condensation integral cannot be derived by substituting Eq. (27) into Eq. (23). Instead, Fountoukis and Nenes (2005) suggested to use an average mass transfer coefficient, $D_{v}$,ave, for the growing droplet population. Assuming that $\alpha_{c}$ is constant for all $\mathrm{CCN}$, and $D_{p}$, low and $D_{p \text {,big }}$ express the upper and lower size of droplets responsible for the condensation of water vapor (hence mass transfer), $D_{v \text {,ave }}$ can be expressed as (Fountoukis and Nenes, 2005):

$D_{v, \text { ave }}=$

$\frac{D_{v}}{D_{p, \text { big }}-D_{p, \text { low }}}\left[\left(D_{p, \text { big }}-D_{p, \text { low }}\right)-B^{\prime} \ln \left(\frac{D_{p, \text { big }}+B^{\prime}}{D_{p, \text { low }}+B^{\prime}}\right)\right]$

where $B^{\prime}=\frac{2 D_{v}}{\alpha_{c}}\left(\frac{2 \pi M_{w}}{R T}\right)^{1 / 2}$. Based on numerical simulations for a wide range of values of conditions, Fountoukis and Nenes, (2005) suggest $D_{p, b i g}=5 \mu \mathrm{m}$ and $D_{p, \text { low }}=\min \left\{0.207683 \alpha_{c}^{-0.33048}, 5.0\right\}$ where $D_{p \text {,low }}$ is given in $\mu \mathrm{m}$.

\subsection{Computing the condensation integral $I_{e}\left(0, s_{\max }\right)$}

To compute the condensation integral (Eq. 25), we first express it as the sum of two terms. The first one gives the contribution from particles that follow Köhler theory, 
$I_{K}\left(0, s_{\max }\right)$, whereas the second one from FHH particles, $I_{\mathrm{FHH}}\left(0, s_{\max }\right)$ :

$I_{e}\left(0, s_{\max }\right)=I_{K}\left(0, s_{\max }\right)+I_{\mathrm{FHH}}\left(0, s_{\max }\right)$

Using the population splitting approach of Nenes and Seinfeld $(2003), I_{K}\left(0, s_{\max }\right)$ is calculated as:

$I_{K}\left(0, s_{\max }\right)=I_{K, 1}\left(0, s_{\text {part }}\right)+I_{K, 2}\left(s_{\text {part }}, s_{\max }\right)$

where $I_{K, 1}\left(0, s_{\text {part }}\right)$ corresponds to Köhler CCN that, at the instant of parcel maximum supersaturation, either do not strictly activate $\left(D_{p} \ll D_{c}\right)$, or experience significant growth beyond their critical diameter $\left(D_{p} \gg D_{c}\right) . \quad I_{K, 2}\left(s_{\text {part }}, s_{\max }\right)$ corresponds to $\mathrm{CCN}$ that have not grown significantly beyond their critical diameter, i.e., $D_{p}^{2}(\tau) \gg 2 G \int_{\tau}^{t_{\max }}$ sdt (Nenes and Seinfeld, 2003). Calculation of the partitioning supersaturation, $s_{\text {part }}$, and $I_{K, 1}\left(0, s_{\text {part }}\right)$ and $I_{K, 2}\left(s_{\text {part }}, s_{\max }\right)$ for sectional and lognormal size distribution formulations are presented in detail by Nenes and Seinfeld (2003), Fountoukis and Nenes (2005), and Barahona and Nenes (2007), and are not repeated here.

$I_{\mathrm{FHH}}\left(0, s_{\max }\right)$ in Eq. (29) represents the contribution of FHH particles to the condensation integral. According to Sect. 2.2, $D_{c} / D_{\text {dry }}<2$ for most atmospherically-relevant combinations of $A_{\mathrm{FHH}}$ and $B_{\mathrm{FHH}}$ (which is much smaller than $\left(D_{c} / D_{\text {dry }}\right)$ for Köhler particles with similar dry diameters). Compared to FHH particles, Köhler particles may require 8 to 125000 times more water (i.e., 2 to 50 times larger wet diameter) to become activated (Table 1). Given that all activated droplets at $s_{\max }$ grow to much larger sizes than their dry diameter and that $D_{c} \sim D_{\text {dry }}$ for FHH particles (hence $D_{p}$ $\left.\gg D_{c}\right), D_{p}^{2}(\tau) \ll 2 G \int_{\tau}^{t_{\text {max }}}$ sdt, and,

$$
\begin{aligned}
& I_{\mathrm{FHH}}\left(0, s_{\max }\right)=G s_{\max } \int_{0}^{s_{\max }}\left(2 G \int_{\tau}^{t_{\max }} \mathrm{sdt}\right)^{1 / 2} n^{s}\left(s^{\prime}\right) d s^{\prime} \\
& \approx G s_{\max } \int_{0}^{s_{\max }}\left(2 G \frac{1}{2 \alpha V}\left(s_{\max }^{2}-s(\tau)^{2}\right)\right)^{1 / 2} n^{s}\left(s^{\prime}\right) d s^{\prime}
\end{aligned}
$$

where $s(\tau)$ is parcel supersaturation at time $\tau$, and, $\int^{t_{\max }} \mathrm{sdt}$ is approximated with the lower bound of Twomey (1959) (Nenes and Seinfeld, 2003).

For sectional representation of aerosol size distributions, $I_{\mathrm{FHH}}\left(0, s_{\mathrm{max}}\right)$ is computed by substituting Eq. (10) into Eq. (31), and performing the integration as follows

$$
\begin{aligned}
& I_{\mathrm{FHH}}\left(0, s_{\max }\right)=G s_{\max }\left(\frac{G}{\alpha V}\right)^{1 / 2} \sum_{j=1}^{i_{\max }} \frac{N_{j}}{s_{c}^{j}-s_{c}^{j-1}} \\
& {\left[\frac{y}{2}\left(s_{\max }^{2}-y^{2}\right)^{1 / 2}+\frac{s_{\max }^{2}}{2} \arcsin \frac{y}{s_{\max }}\right]_{y=s_{c}^{j-1}}^{y=s_{c}^{j}}}
\end{aligned}
$$

where $i_{\max }$ is the boundary closest to $s_{\max }$.
For lognormal representation of aerosol size distribution, $I_{\mathrm{FHH}}\left(0, s_{\max }\right)$ is computed by substituting Eq. (17) into Eq. (31), and integrating

$$
\begin{aligned}
& I_{\mathrm{FHH}}\left(0, s_{\max }\right)=G\left(\frac{G}{\alpha V}\right)^{1 / 2} \frac{N_{i} s_{\max }^{2}}{2} \\
& {\left[1-\left(\frac{s_{g, i}}{s_{\max }}\right)^{2} \frac{\exp \left(2 x^{2} \ln ^{2} \sigma_{i}\right)\left(\operatorname{erf}\left(\sqrt{2} x \sigma_{i}-u_{\max }\right)+1\right)}{2}-\operatorname{erf}\left(u_{\max }\right)\right]}
\end{aligned}
$$

where $u_{\max }=\frac{\ln \left(s_{g, i} / s_{\max }\right)^{-\frac{1}{x}}}{\sqrt{2} \ln \sigma_{i}}$. In the case of multiple lognormal modes, the right-hand side of Eq. (33) is summed over all lognormal modes.

\subsection{Using the parameterization}

The parameterization algorithm is illustrated in Fig. 6, and consists of two steps. First, Eq. (24) is numerically solved for $s_{\max }$ using the bisection method:

$\frac{\pi \gamma \rho_{w}}{2 \alpha V \rho_{a}}\left[I_{K, 1}\left(0, s_{\mathrm{part}}\right)+I_{K, 2}\left(s_{\mathrm{part}}, s_{\max }\right)+I_{\mathrm{FHH}}\left(0, s_{\max }\right)\right]-1=0$

where the condensation integral is substituted with the desirable formulation (sectional or lognormal). Physical properties are evaluated at the cloud base conditions for adiabatic updrafts (i.e., $e=0$ ). For entraining parcels (i.e., $e>0$ ), properties are evaluated at the critical entrainment rate following the procedure of Barahona and Nenes (2007). Once $s_{\max }$ is determined, $N_{d}$ is obtained from Eq. (26).

\section{Evaluation of the parameterization}

\subsection{Method}

We first test the sectional formulation against the lognormal formulation to show the equivalence between the two. Then, we evaluate the accuracy of the parameterization by comparing the predicted droplet number concentration and maximum supersaturation against the numerical parcel model of Nenes et al. (2001); (modified to include FHH particles) for a wide range of size distributions representative of global aerosols.

\subsection{Evaluation of involved parameters}

Nenes and Seinfeld (2003), Fountoukis and Nenes (2005) and Barahona and Nenes (2007) have extensively evaluated the parameterization for aerosol composed of only Köhler particles. Therefore, the focus of this evaluation is on the performance of the parameterization when FHH particles are externally mixed with Köhler particles, considering a wide range of $A_{\mathrm{FHH}}, B_{\mathrm{FHH}}$, water vapor accommodation coefficient, $\alpha_{c}$, and parcel updraft velocity, $V$. The values of $\alpha_{c}$ and $V$ were selected to represent typical conditions encountered in low-level cumulus and stratocumulus clouds of marine and continental origin (Pontikis et al., 1987; Conant et 
Table 5. Whitby (Whitby, 1978) Aerosol lognormal size distributions used in this study.

\begin{tabular}{lllrllrllll}
\hline & \multicolumn{3}{c}{ Nuclei Mode } & \multicolumn{3}{c}{ Accumulation Mode } & \multicolumn{3}{c}{ Coarse Mode } \\
\hline Aerosol Type & $D_{g 1}$ & $\sigma_{1}$ & $N_{1}$ & $D_{g 2}$ & $\sigma_{2}$ & $N_{2}$ & $D_{g 3}$ & $\sigma_{3}$ & $N_{3}$ \\
Marine & 0.010 & 1.6 & 340 & 0.070 & 2.0 & 60 & 0.62 & 2.7 & 3.1 \\
Continental & 0.016 & 1.6 & 1000 & 0.068 & 2.1 & 800 & 0.92 & 2.2 & 0.72 \\
Background & 0.016 & 1.7 & 6400 & 0.076 & 2.0 & 2300 & 1.02 & 2.16 & 3.2 \\
Urban & 0.014 & 1.8 & 106000 & 0.054 & 2.16 & 32000 & 0.86 & 2.21 & 5.4 \\
\hline
\end{tabular}

$D_{g i}$ is the median diameter $(\mu \mathrm{m}), N_{i}$ is the number of dry particles $\left(\mathrm{cm}^{-3}\right)$, and $\sigma_{i}$ is the geometric standard deviation of the $i^{\text {th }}$ mode.

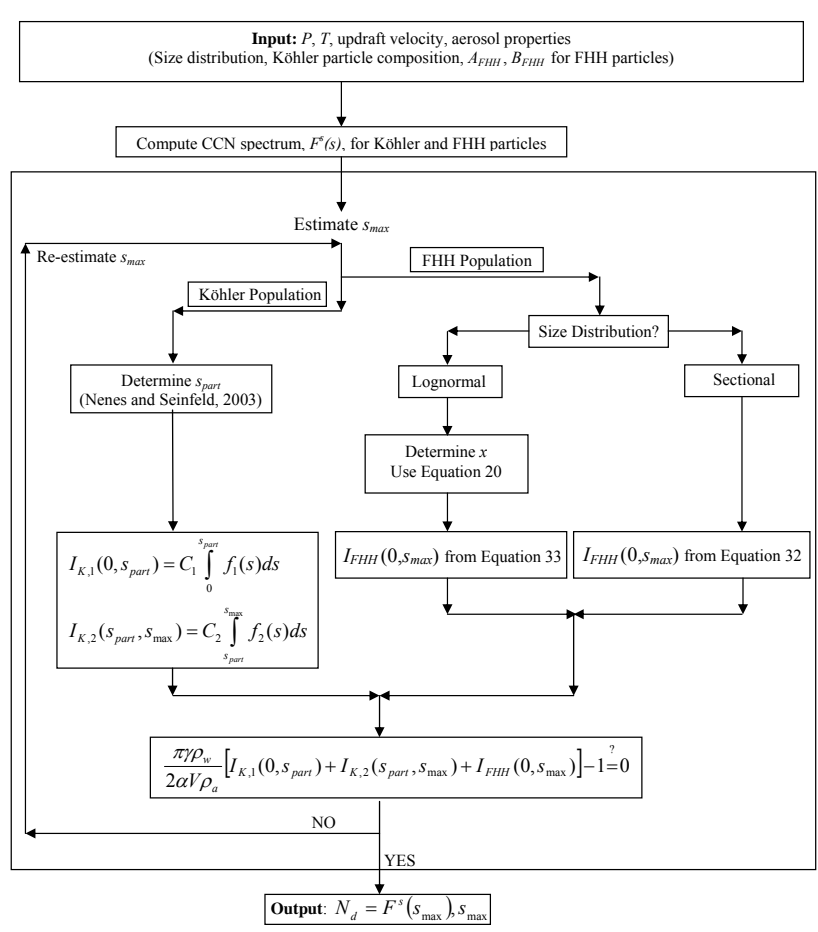

Fig. 6. Parameterization Algorithm. $C_{1}, C_{2}, f_{1}(s), f_{2}(s)$ depend on the aerosol representation (sectional, lognormal) and are defined in Nenes and Seinfeld (2003).

al., 2004; Meskhidze et al., 2005; Peng et al., 2005, Fountoukis et al., 2007). In total, 6600 simulations were performed (see Tables 2, 5 and 6).

For this comparison, we selected four Whitby (1978) trimodal size distributions, namely marine, clean continental, average background, and urban (Table 5). In addition, we selected four aerosol distributions that are representative of ambient dust (Jeong and Sokolik, 2007), the properties of which are given in Table 6, and are C04 (Clarke et al., 2004), D87 (D’Almeida, 1987), 098 (Hess et al., 1998), and W08 (Wiegner et al., 2008). As expected, the distributions given by Whitby have smaller median diameters in comparison to typical dust distributions. For each aerosol size distribution, we consider a parcel of externally mixed Köhler and FHH parti-
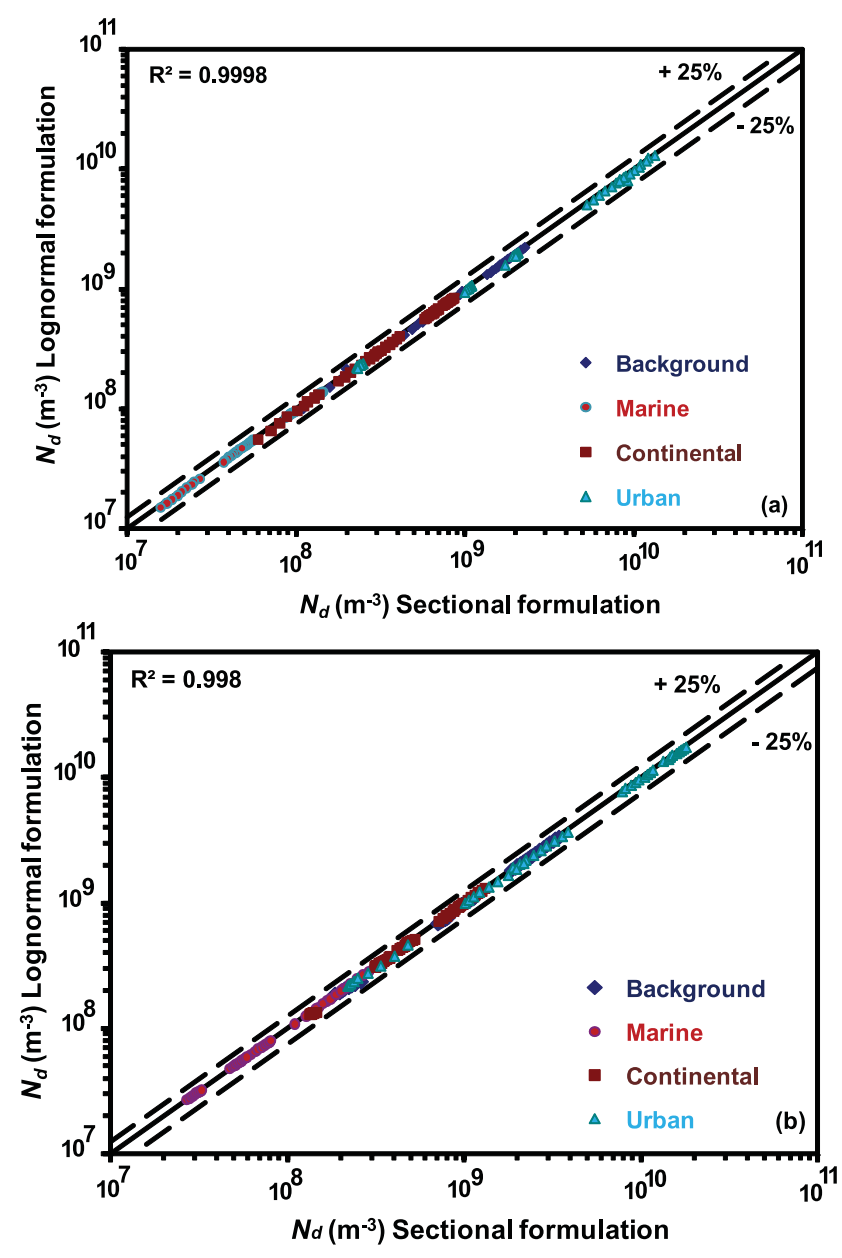

Fig. 7. Droplet number concentration, $N_{d}\left(\mathrm{~m}^{-3}\right)$, predicted by the sectional and the lognormal formulations for Whitby (1978) distributions and for the cloud formation conditions of Table 2 . Results are shown for (a) $\alpha_{c}=0.042$, and $A_{\mathrm{FHH}}=0.68$ and $B_{\mathrm{FHH}}=0.93$ and (b) $\alpha_{c}=0.06$, and $A_{\mathrm{FHH}}=2.00$ and $B_{\mathrm{FHH}}=1.00$. Dashed lines represent $\pm 25 \%$ deviation.

cles, allowing the proportion to vary from $0 \%$ (pure Köhler particles) to $100 \%$ (pure FHH particles) by number. For each FHH particle, we assume $100 \%$ of the mass is insoluble with 
Table 6. Aerosol lognormal size distributions used in this study that are representative of mineral dust aerosol (see Jeong and Sokolik, 2007).

\begin{tabular}{llllllllllccc}
\hline & \multicolumn{3}{c}{ Mode 1 } & \multicolumn{3}{c}{ Mode 2 } & & Mode 3 & \multicolumn{3}{c}{ Mode 4 } \\
\hline Size Distribution & $\mathrm{D}_{g 1}$ & $\sigma_{1}$ & $\mathrm{MF}_{1} \%$ & $\mathrm{D}_{g 2}$ & $\sigma_{2}$ & $\mathrm{MF}_{2} \%$ & $\mathrm{D}_{g 3}$ & $\sigma_{3}$ & $\mathrm{MF}_{3} \%$ & $\mathrm{D}_{g 4}$ & $\sigma_{4}$ & $\mathrm{MF}_{4} \%$ \\
C04 (Clarke et al., 2004) & 0.69 & 1.46 & 1.8 & 1.77 & 1.85 & 69.4 & 8.67 & 1.50 & 28.8 & - & - & - \\
D87 (D'Almeida, 1987) & 0.16 & 2.10 & 1.0 & 1.40 & 1.90 & 95.3 & 9.98 & 1.60 & 3.7 & - & - & - \\
O98 (Hess et al., 1998) & 0.14 & 1.95 & 3.4 & 0.78 & 2.00 & 76.1 & 3.80 & 2.15 & 20.5 & - & - & - \\
W08 (Wiegner et al., 2008) & 0.078 & 2.2 & 2.93 & 0.495 & 1.7 & 0.81 & 1.40 & 1.9 & 31.53 & 6.50 & 1.7 & 64.73 \\
\hline
\end{tabular}

$D_{g i}$ is the median diameter $(\mu \mathrm{m}), \sigma_{i}$ is the geometric standard deviation, and $M F_{i} \%$ is the percentage mass fraction of dry particles of the $i^{\text {th }}$ mode. Particle number concentration was calculated from percentage mass fraction by assuming a total mass equal to $4000 \mu \mathrm{g} \mathrm{m}^{-3}$ and particle density equal to $2.5 \mathrm{~g} \mathrm{~cm}^{-3}$ in the first three distributions. For Wiegner et al. (2008), number concentration was converted to percentage mass fraction of dry particles in each mode.

Table 7. Droplet number agreement between the parameterization and parcel model, for each aerosol type and conditions in Table 2.

\begin{tabular}{lcc}
\hline Aerosol Type & $\begin{array}{c}\text { Relative } \\
\text { Error }\end{array}$ & $\begin{array}{c}\text { (\%) Standard } \\
\text { Deviation }\end{array}$ \\
\hline Whitby Background (Whitby, 1978) & +5 & \pm 12 \\
Whitby Marine (Whitby, 1978) & -20 & \pm 10 \\
Whitby Continental (Whitby, 1978) & +2 & \pm 6 \\
Whitby Urban (Whitby, 1978) & +7 & \pm 17 \\
C04 (Clarke et al, 2004) & +2 & \pm 5 \\
D87 (D'Almeida, 1987) & +8 & \pm 12 \\
O98 (Hess et al., 1998) & +2 & \pm 15 \\
W08 (Wiegner et al., 2008) & +4.5 & \pm 25 \\
\hline
\end{tabular}

activating properties given by $A_{\mathrm{FHH}}$ and $B_{\mathrm{FHH}}$. Each Köhler particle has a $50 \%$ soluble $\left(\mathrm{NH}_{4}\right)_{2} \mathrm{SO}_{4}$ and $50 \%$ insoluble material by mass. $A_{\mathrm{FHH}}$ was varied between 0.25 and 2.0, and $B_{\mathrm{FHH}}$ from 0.93 to 2.50 . The parcel pressure and temperature were $900 \mathrm{mbar}$ and $298 \mathrm{~K}$, respectively, and droplet concentration was computed at $350 \mathrm{~m}$ above the cloud base.

\subsection{Comparison of sectional against lognormal formu- lation}

The sectional formulation is evaluated against the lognormal formulation by comparing $N_{d}$ predicted by the application of each formulation to the activation of lognormal aerosol size distributions shown in Tables 5 and 6 . In applying the sectional formulation, 75 sections per mode were used to discretize the lognormal distributions. The intercomparison is shown in Fig. 7, which depicts the parameterized $N_{d}$ using the sectional versus the lognormal formulation. Figure 7a compares Whitby (1974) aerosol size distributions, for $\alpha_{c}=0.042, A_{\mathrm{FHH}}$ equal to 0.68 , and $B_{\mathrm{FHH}}$ equal to 0.93 while Fig. 7b shows comparisons for $\alpha_{c}=0.06, A_{\mathrm{FHH}}$ equal to 2.00 , and $B_{\mathrm{FHH}}$ equal to 1.00 . An excellent agreement between the two formulations is obtained for all cases considered ( $R^{2}=0.9998$ and $\left.R^{2}=0.998\right)$, suggesting both formulations are equivalent.

\subsection{Comparison of sectional parameterization with par- cel model}

\subsubsection{Whitby aerosol distribution}

Figure 8 shows that the parameterized droplet number closely follows closely follows the predicted droplet number from the parcel model for all conditions of Table 2, thus indicating that there are no regions with systematic biases in the predictions (Fig. 8a average relative error: $0.37 \% \pm 16 \%$, and, Fig. $8 \mathrm{~b}$ average relative error: $0.15 \% \pm 17 \%$ ). Figure 9 shows the comparison for the predicted droplet number between the parameterization and the parcel model for individual Whitby (1978) distributions. An excellent agreement is apparent, with an average relative error of less than $10 \%$ (Table 7). The only exception is the case of the marine aerosol size distribution, where a minor systematic overprediction in parameterized $N_{d}$ is observed. According to Barahona and Nenes (2007), this bias originates from an underestimation of the droplet size and total surface area for water vapor condensation. This in turn underestimates the condensation integral, thereby resulting in an overestimation in $s_{\max }$, and $N_{d}$.

\subsubsection{Dust size distributions}

To test the applicability of this new parameterization to distributions representative of dust, we performed an extensive analysis on droplet number predictions comparisons between this parameterization and the parcel model on aerosol distributions suggested by C04 (Clarke et al., 2004), D87 (D’Almeida, 1987), O98 (Hess et al., 1998) and W08 (Wiegner et al., 2008) for the cloud conditions of Table 2.

Figure 10 shows predictions of droplet number concentration for all conditions of parcel updrafts, uptake coefficients, and for different dust distributions, assuming $A_{\mathrm{FHH}}$ equal to 0.68 , and $B_{\mathrm{FHH}}$ equal to 0.93 . A good agreement is observed between the parameterization and the parcel model for different updrafts and $\alpha_{c}=0.042$ (Fig. 10a), $\alpha_{c}=0.06$ (Fig. 10b), and, $\alpha_{c}=1.0$ (Fig. 10c). The agreement is best at high updrafts $\left(5 \mathrm{~m} \mathrm{~s}^{-1}, 10 \mathrm{~m} \mathrm{~s}^{-1}\right)$; at low updrafts 

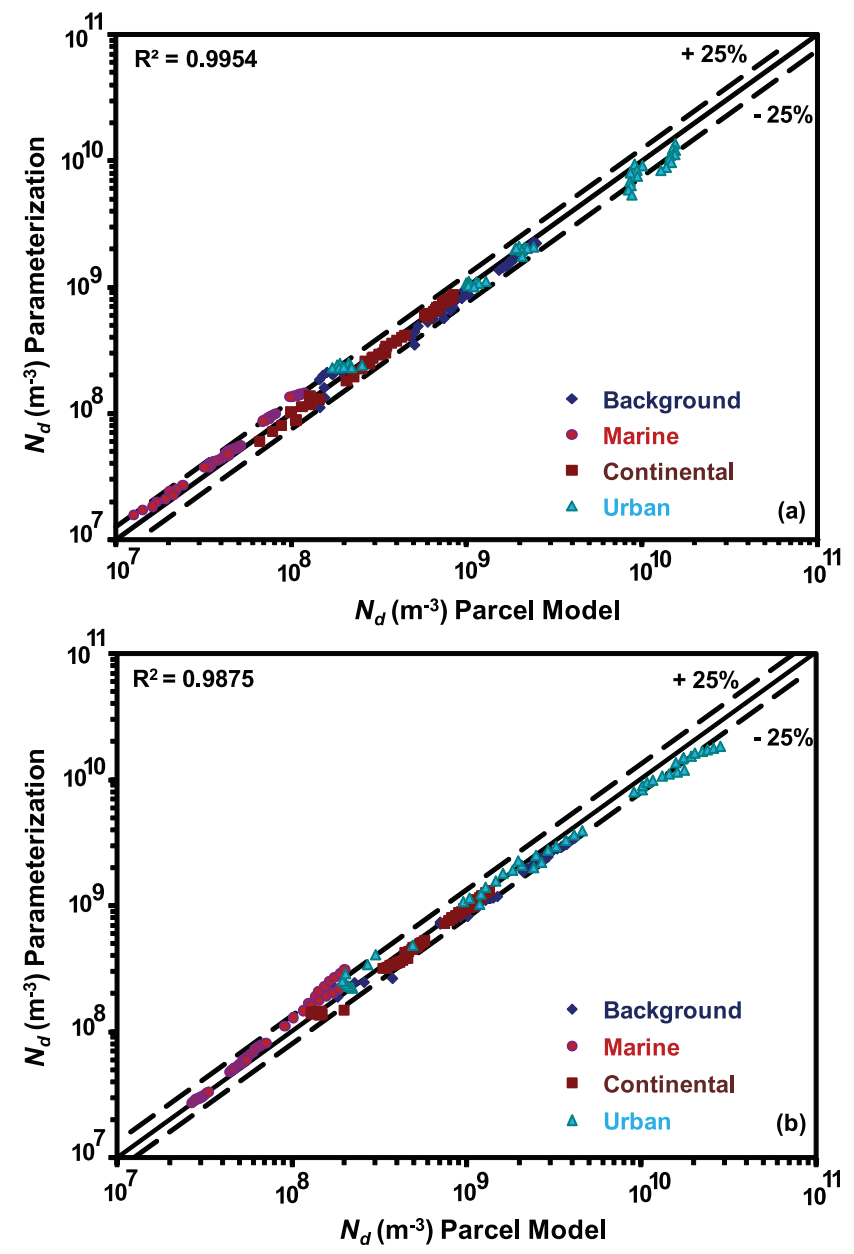

Fig. 8. Droplet number concentration, $N_{d}\left(\mathrm{~m}^{-3}\right)$, predicted by parameterization and the parcel model for Whitby (1978) distributions, for the cloud formation conditions of Table 2. Results are shown for (a) $\alpha_{c}=0.042$, and $A_{\mathrm{FHH}}=0.68$ and $B_{\mathrm{FHH}}=0.93$ and (b) $\alpha_{c}=0.06$, and $A_{\mathrm{FHH}}=2.0$ and $B_{\mathrm{FHH}}=1.0$. Dashed lines represent $\pm 25 \%$ deviation.

$\left(0.1 \mathrm{~m} \mathrm{~s}^{-1}, 0.5 \mathrm{~m} \mathrm{~s}^{-1}\right)$ overprediction by the parameterized $N_{d}$ was observed. This is because of the overprediction in maximum parcel supersaturation, $s_{\max }$ (Fig. 11), from an underprediction in droplet size, as explained in Sect. 4.4.1. The best performance is seen using the W08 (Wiegner et al., 2008) dust distribution (Fig. 11d). This may be attributed to smaller median diameters for the W08 (Wiegner et al., 2008) distribution in comparison to the much larger fraction of particles greater than 1 micron present in the $\mathrm{C} 04$ (Clarke et al., 2004), D87 (D’Almeida, 1987), and O98 (Hess et al., 1998) distributions.

Figure 11 compares parcel maximum supersaturation, $s_{\max }$, between the parcel model and the parameterization for three different values of accommodation coefficients. At low values of $\alpha_{c}$, a greater overprediction in $s_{\max }$ is observed.
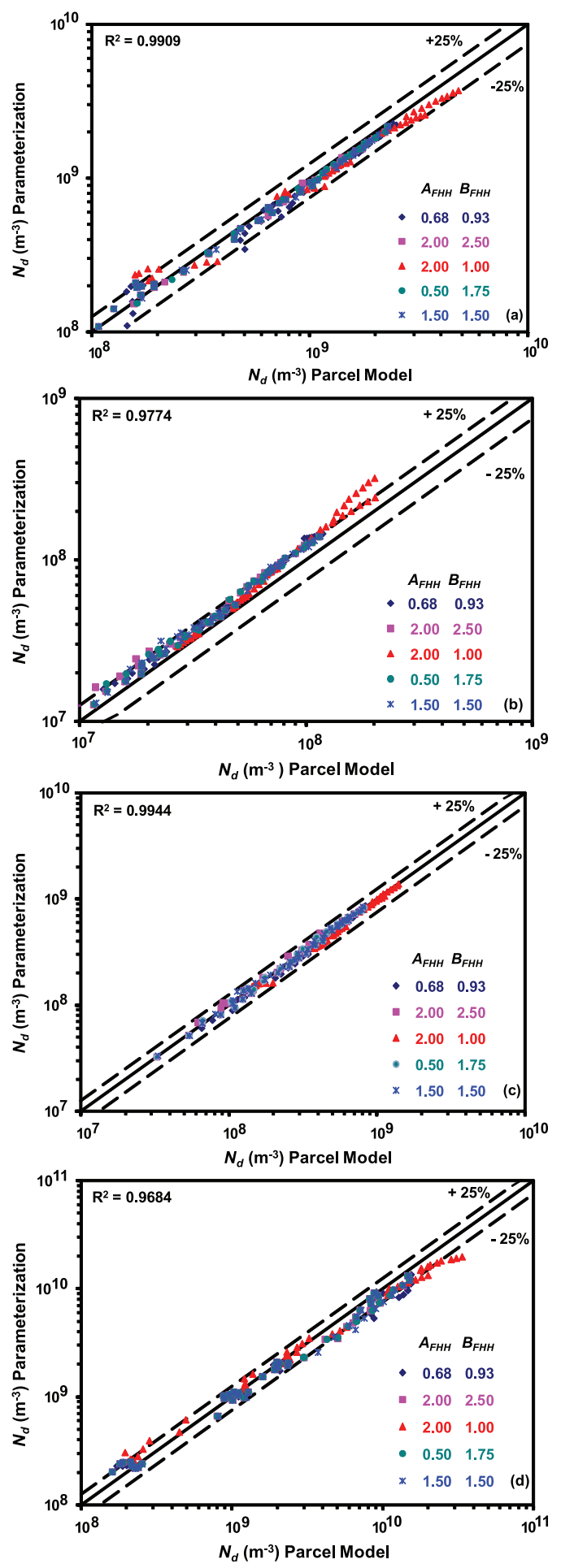

Fig. 9. Droplet number concentration, $N_{d}\left(\mathrm{~m}^{-3}\right)$, predicted by parameterization and the parcel model for Whitby (1978) distributions, (a) Background, (b) Marine, (c) Continental, and (d) Urban, for the cloud formation conditions of Table 2. Results are shown for $\alpha_{c}=0.042$ and five different combination of $A_{\mathrm{FHH}}$ and $B_{\mathrm{FHH}}$. Dashed lines represent $\pm 25 \%$ deviation. 

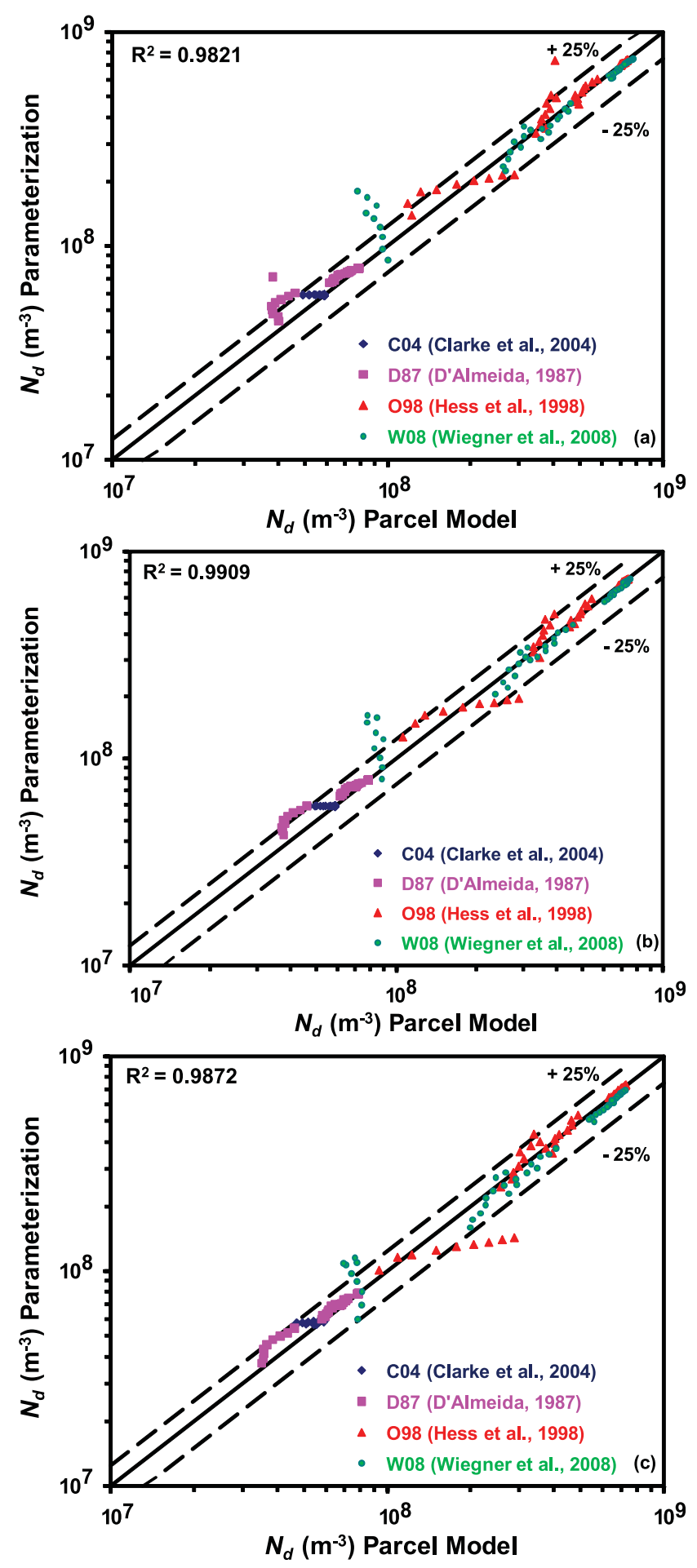

Fig. 10. Droplet number concentration, $N_{d}\left(\mathrm{~m}^{-3}\right)$, predicted by the parameterization and the parcel model for the dust size distributions of Table 6, and the cloud formation conditions of Table 2. Results are shown for $A_{\mathrm{FHH}}=0.68$ and $B_{\mathrm{FHH}}=0.93$ and (a) $\alpha_{c}=0.042$, (b) $\alpha_{c}=0.06$, and (c) $\alpha_{c}=1.0$. Dashed lines represent $\pm 25 \%$ deviation.
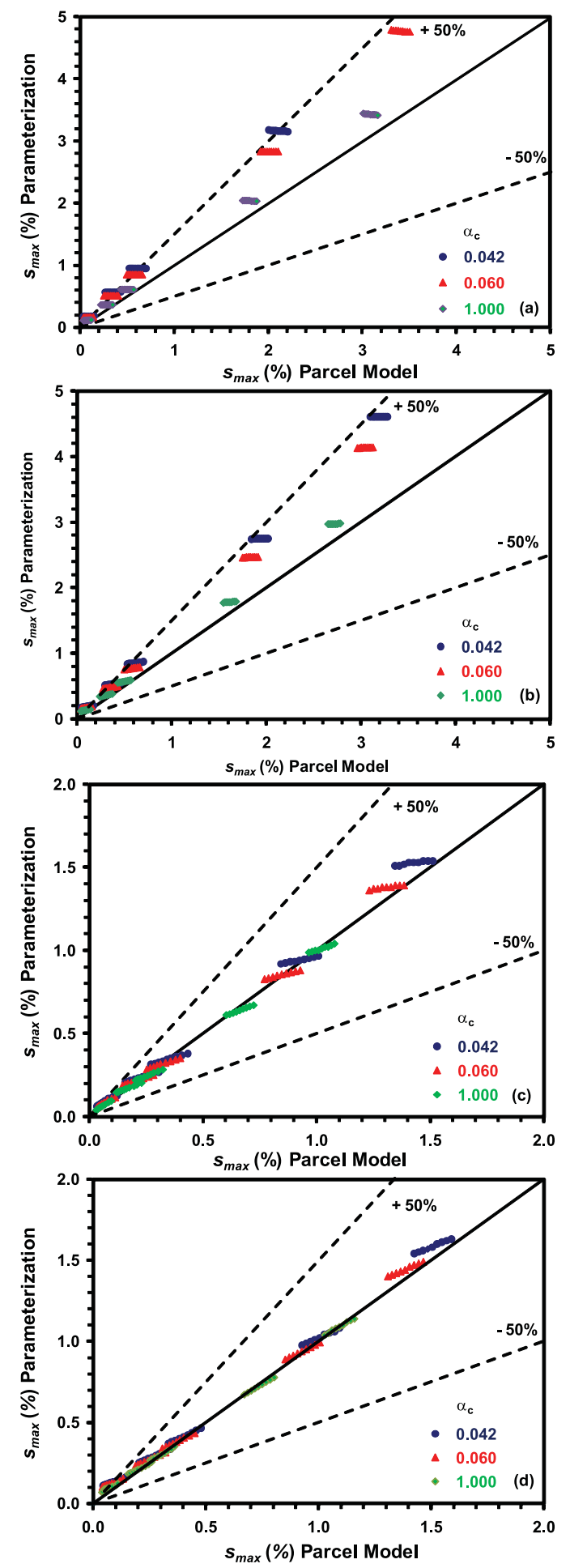

Fig. 11. Parcel maximum supersaturation, $s_{\max }$, predicted by the parameterization and the parcel model, for the $V, \alpha_{c}$ conditions of Table 2, and dust size distributions of (a) C04 (Clarke et al., 2004), (b) D87 (D'Almeida, 1987), (c) O98 (Hess et al., 1998) and, (d) W08 (Wiegner et al., 2008) for $A_{\mathrm{FHH}}=0.68$ and $B_{\mathrm{FHH}}=0.93$ in all simulations. Dashed lines represent $\pm 50 \%$ deviation 


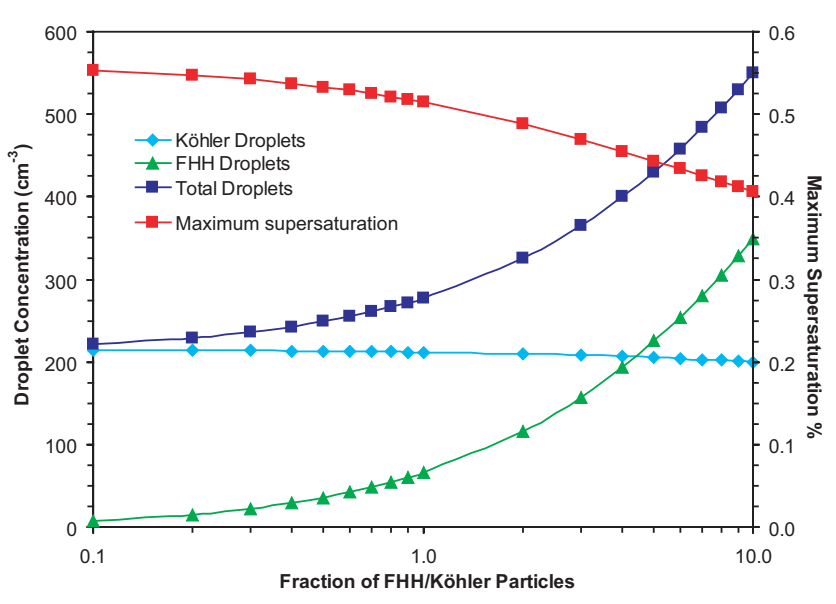

Fig. 12. Predicted total number of cloud droplets (blue curve) as a function of $\mathrm{FHH}$ to Köhler particle concentration ratio, for the conditions described in Sect. 5. Also shown are the contribution of Köhler (cyan curve) and FHH (green curve) particles to the droplet number, as well as the maximum supersaturation (red curve) that develops in the parcel.

This consequently results in overprediction in the number of activated droplets, and manifests because of the underestimation of surface area available for water vapor condensation for the largest size of $\mathrm{CCN}$ as explained in Sect. 4.4.1. However, this overestimation in cloud droplet number becomes important only for very large values of $s_{\max }$ that are not found in clouds. Inspite of this overprediction in the cloud droplet number, we find that the average relative error for all dust representative distributions (Table 6) is well below 10\% (Table 7).

\section{On the competition of FHH with Köhler particles for water vapor}

In this section, we provide a first evaluation of the potential impact of adsorption activation on cloud droplet number. For this, it is assumed that the aerosol is an external mixture of Köhler and FHH particles, both of which are described with a single-mode lognormal size distribution obtained from in-situ measurements during the NAMMA campaign (Twohy et al., 2009). The geometric mean diameter, $D_{g}$, and standard deviation, $\sigma_{g}$, were identical for both particle types $\left(D_{g}=0.10 \mu \mathrm{m}, \sigma_{g}=1.6\right)$; the total concentration of Köhler particles were maintained constant in all simulations, equal to $225 \mathrm{~cm}^{-3}$, while the concentration of $\mathrm{FHH}$ particles was varied from 22.5 to $2250 \mathrm{~cm}^{-3}$. The Köhler particles were assumed to be composed of pure $\left(\mathrm{NH}_{4}\right)_{2} \mathrm{SO}_{4}$, while size-resolved activation data of Saharan dust (Twohy et al., 2009) were used to constrain values of $A_{\mathrm{FHH}}(=0.46)$, $B_{\mathrm{FHH}}(=0.85)$ (through least squares fitting to Eq. 13) for the FHH particles. In all simulations presented, the updraft ve- locity in the cloud parcel is set to $0.5 \mathrm{~m} \mathrm{~s}^{-1}$, and initial pressure and temperature are $273 \mathrm{~K}$ and $600 \mathrm{mbar}$, respectively.

Figure 12 shows the predicted total cloud droplet number (blue curve) as a function of FHH to Köhler particle concentration ratio. Also shown are the contribution of Köhler (cyan curve) and FHH (green curve) particles to the droplet number, as well as the maximum supersaturation (red curve) that develops in the parcel. At low FHH/Köhler concentration ratio, all of the droplets in the cloud parcel originate from the Köhler particles. As the number concentration of FHH particles increases, the number of droplets from adsorption activation increases; the resulting competition for water vapor depresses $s_{\max }$ and slightly decreases the droplet number forming from Köhler particles. The competition effect however of FHH particles water vapor is weaker compared to similar effects from Köhler particles (Ghan et al., 1998), because the amount of water required for activation of the former $\left(D_{c} / D_{\text {dry }} \sim 1\right)$ is smaller than for the latter $\left(D_{c} \gg D_{\text {dry }}\right)$. As a result, droplet number may respond much more strongly to increases in FHH aerosol number than for Köhler aerosol. A thorough quantification requires a comprehensive investigation and will be the subject of a future study.

\section{Summary}

This study presents a new parameterization of cloud droplet formation for an external mixture of soluble particles that activate according to Köhler theory, and, completely insoluble, wettable particles that form droplets through adsorption activation (following FHH adsorption theory). This new parameterization is the first of its kind and is built upon previous work of Nenes and Seinfeld (2003), Fountoukis and Nenes (2005), and Barahona and Nenes (2007).

Formulation of the parameterization is developed for sectional and lognormal representations of the aerosol size distribution. To facilitate the analytical development of the parameterization, we have further developed FHH activation theory by $i$ ) determining the combinations of $A_{\mathrm{FHH}}$ and $B_{\mathrm{FHH}}$ for atmospherically-relavent behaviour, and, ii) linking critical supersaturation with dry diameter using a simple power law expression, determined from numerical solutions to the FHH equilibrium curves.

The parameterization is tested by comparing predictions of droplet number and $s_{\max }$ against detailed cloud parcel model simulations. The evaluations are performed for a range of updraft velocity, water vapor uptake coefficient, ambient temperature, relative humidity, parameters of aerosol size distribution, and $A_{\mathrm{FHH}}$ and $B_{\mathrm{FHH}}$. The parameterization closely follows the parcel model simulations with a mean relative error varying between $2 \%$ and $20 \%$ depending on aerosol distribution type with an average relative error of $10 \%$ and $R^{2} \sim 0.98$.

Future work is needed to experimentally derive appropriate values of $A_{\mathrm{FHH}}$ and $B_{\mathrm{FHH}}$ for dust, soot and other 
insoluble atmospheric particles. Once available, the framework presented here is uniquely placed for addressing questions related to the interactions of insoluble particles with clouds and climate.

Acknowledgements. This work was supported by NOAA ACC, NSF CAREER and NASA grants. We would also like to acknowledge two anonymous referees for comments that substantially improved the manuscript. We also thank Donifan Barahona for valuable discussions and help in computer coding.

Edited by: J. Seinfeld

\section{References}

Abdul-Razzak, H. and Ghan, S. J.: A parameterization of aerosol activation: 2. Multiple aerosol types, J. Geophys. Res., 105(D6), 6837-6844, 2000.

Abdul-Razzak, H., Ghan, S. J., and Rivera-Carpio, C.: A parameterization of aerosol activation: 1. Single aerosol type, J. Geophys. Res., 103(D6), 6123-6131, 1998.

Albrecht, B. A.: Aerosols, cloud microphysics, and fractional cloudiness, Science, 245, 1227-1230, 1989.

Asa-Awuku, A. and Nenes, A.: The effect of solute dissolution kinetics on cloud droplet formation: Extended Köhler theory, J. Geophys. Res., 112, D22201, doi:10.1029/2005JD006934, 2007.

Barahona, D. and Nenes, A.: Parameterization of cloud droplet formation in large-scale models: Including effects of entrainment, J. Geophys. Res., 112, D16206, doi:10.1029/2007JD008473, 2007.

Boucher, O. and Lohmann, U.: The sulfate-CCN-cloud albedo effect: A sensitivity study with 2 general circulation models, Tellus, Ser. B, 47, 281-300, 1995.

Brunauer, S., Emmett, P. H., and Teller, E.: Adsorption of gases in multimolecular layers, J. Am. Chem. Soc., 60(2), 309-319, 1938.

Clarke, A. D., Shinozuka, Y., Kapustin, V. N., Howell, S., Huebert, B., Doherty, S., Anderson, T., Covert, D., Anderson, J., Hua, X., Moore II, K. G., McNaughton, C., Carmichael, G., and Weber, R.: Size distributions and mixtures of dust and black carbon aerosol in Asian outflow: Physiochemistry and optical properties, J. Geophys. Res., 109, D15S09, doi:10.1029/2003JD004378, 2004.

Cohard, J.-M., Pinty, J.-P., and Suhre, K.: On the parameterization of activation spectra from cloud condensation nuclei microphysical properties, J. Geophys. Res., 105(D9), 11753-11766, 2000.

Conant, W. C., Van Reken, T. M., Rissman, T. A., Varutbangkul, V., Jonsson, H. H., Nenes, A., Jimenez, J. L., Delia, A. E., Bahreini, R., Roberts, G. C., Flagan, R. C., and Seinfeld, J. H.: Aerosolcloud drop concentration closure in warm cumulus, J. Geophys. Res., 109, D13204, doi:10.1029/2003JD004324, 2004.

D'Almeida, G. A.: On the variability of desert aerosol radiative characteristics, J. Geophys. Res., 92, 3017-3027, 1987.

Feingold, G. and Chuang, P.: Analysis of the Influence of FilmForming compounds on Droplet Growth: Implications for Cloud Microphysical Processes and Climate, J. Atmos. Sci., 59, 20062018, 2002.

Feingold, G. and Heymsfield, A. J.: Parameterization of condensational growth of droplets for use in general circulation models, J. Atmos. Sci, 49, 2325-2342, 1992.
Fletcher, N. H.: Size effect in heterogeneous nucleation, J. Chem. Phys., 29, 572-576, 1958.

Forster, P., Ramaswamy, V., Artaxo, P., Berntsen, T., Betts, R., Fahey, D. W., Haywood, J., Lean, J., Lowe, D. C., Myhre, G., Nganga, J., Prinn, R., Raga, G., Schulz, M., and Van Dorland, R.: Changes in Atmospheric Constituents and in Radiative Forcing, in: Climate Change 2007: The Physical Science Basis. Contribution of Working Group I to the Fourth Assessment Report of the Intergovernmental Panel on Climate Change, edited by: Solomon, S., Qin, D., Manning, M., Chen, Z., Marquis, M., Averyt, K. B., Tignor, M., and Miller, H. L., Cambridge University Press, Cambridge, UK and New York, NY, USA, 129-234, 2007.

Fountoukis, C. and Nenes, A.: Continued development of a cloud droplet formation parameterization for global climate models, J. Geophys. Res., 110, D11212, doi:10.1029/2004JD005591, 2005.

Fukuta, N. and Walter, L. A.: Kinetics of hydrometer growth from the vapor; spherical model, J. Atmos. Sci., 27, 1160-1172, 1970.

Ghan, S., G. Guzman, and H. Abdul-Razzak: Competition between sea-salt and sulfate particles as cloud condensation nuclei, J. Atmos. Sci., 55, 3340-3347, 1998.

Gultepe, I. and Isaac, G. A.: The relationship between cloud droplet and aerosol number concentrations for climate models, Int. J. Climatol., 16, 941-946, 1996.

Henson, B. F.: An adsorption model of insoluble particle activation: Application to black carbon, J. Geophys. Res., 112, D24S16, doi:10.1029/2007JD008549, 2007.

Hess, M., Koepke, P., and Schult, I.: Optical Properties of Aerosols and Clouds: The Software Package OPAC, B. Am. Meteor. Soc., 79, 831-844, 1998.

Jeong, G.-R. and Sokolik, I. N.: Effect of mineral dust aerosols on photolysis rates in clean and polluted marine environments, J. Geophys. Res., 112, D21308, doi:10.1029/2007JD008442, 2007.

Khvorostyanov, V. I. and Curry, J. A.: Refinements to the Köhler's theory of aerosol equilibrium radii, size spectra and droplet activation: Effects of humidity and insoluble fraction, J. Geophys. Res., 112, D05206, doi:10.1029/2006JD007672, 2007.

Köhler, H.: The nucleus in and the growth of hygroscopic droplets, Trans. Faraday Soc., 32(2), 1152-1161, 1936.

Langmuir, J.: The constitution and fundamental properties of solids and liquids. Part I. Solids, J. Am. Chem. Soc., 38, 2221-2295, 1916.

Lowell, S., Shields, J. E., Thomas, M. A., and Thommes, M.: Characterization of Porous Solids and Powders: Surface Area, Pore Size and Density, Kluwer Academic Publishers, The Netherlands, 24-26, 2004.

Meskhidze, N., Nenes, A., Conant, W. C., and Seinfeld, J. H.: Evaluation of a new cloud droplet activation parameterization with in situ data from CRYSTAL-FACE and CSTRIPE, J. Geophys. Res., 110, D16202, doi:10.1029/2004JD005703, 2005.

Ming, Y., Ramaswamy, V., Donner, L. J., and Phillips, V. T. J.: A new parameterization of cloud droplet activation applicable to general circulation models, J. Atmos. Sci., 63, 1348-1356, 2006.

Nenes, A., Ghan, S. J., Abdul-Razzak, H., Chuang, P. Y., and Seinfeld, J. H.: Kinetic limitations on cloud droplet formation and impact on cloud albedo, Tellus, Ser. B, 53, 133-149, 2001.

Nenes, A. and Seinfeld, J. H.: Parameterization of cloud droplet formation in global climate models, J. Geophys. Res., 108(D14), 4415, doi:10.1029/2002JD002911, 2003.

Nenes, A., Charlson, R. J., Facchini, M. C., Kulmala, M., Laak- 
sonen, A., and Seinfeld, J. H.: Can chemical effects on cloud droplet number rival the first indirect effect?, Geophys. Res. Lett., 29(17), 1848, doi:10.1029/2002GL015295, 2002.

Peng, Y., Lohmann, U., and Leaitch, W. R.: Importance of vertical velocity variations in the cloud droplet nucleation process of marine stratocumulus, J. Geophys. Res., 110, D21213, doi:10.1029/2004JD004922, 2005.

Pontikis, C. A., Rigaud, A., and Hicks, E. M.: Entrainment and mixing as related to the microphysical properties of shallow warm cumulus clouds, J. Atmos. Sci., 44, 2150-2165, 1987.

Seinfeld, J. H. and Pandis, S. N.: Atmospheric Chemistry and Physics, John Wiley, New York, USA, 767-773, 1998.

Seisel, S., Pashkova, A., Lian, Y., and Zellner, R.: Water uptake on mineral dust and soot: A fundamental view of hydrophilicity of atmospheric particles?, Faraday Discuss., 130, 437-451, 2005.

Sorjamaa, R. and Laaksonen, A.: The effect of $\mathrm{H}_{2} \mathrm{O}$ adsorption on cloud drop activation of insoluble particles: a theoretical framework, Atmos. Chem. Phys., 7, 6175-6180, 2007

Twohy, C. H., Kreidenweis, S. M., Eidhammer, T., Browell, E. V., Heymsfield, A. J., Bansemer, A. R., Anderson, B. E., Chen, G., Ismail, S., DeMott, P. J., and Van Den Heever, S. C.: Saharan dust particles nucleate droplets in eastern Atlantic clouds, Geophys. Res. Lett., 36, 1-6, 2009.
Twomey, S.: The nuclei of natural cloud formation part II: The supersaturation in natural clouds and the variation of cloud droplet concentration, Pure Appl. Geophys., 43, 243-249, 1959.

Twomey, S.: Pollution and the planetary albedo, Atmos. Environ., 8, 1251-1256, 1974.

Wexler, A. S. and Ge, Z. Z.: Hydrophobic particles can activate at lower relative humidity than slightly hygroscopic ones: a Köhler theory incorporating surface fixed charge, J. Geophys. Res., 103(D6), 6083-6088, 1998.

Whitby, K. T.: The physical characteristics of sulfur aerosols, Atmos. Environ., 12, 135-139, 1978.

Wiegner, M., Gasteiger, J., Kandler, K., Weinzierl, B., Rasp, K., Esselborn, M., Freudenthaler, V., Heese, B., Toledano, C., Tesche, M., and Althausen, D.: Numerical simulations of optical properties of Saharan dust aerosols with emphasis on linear depolarization ratio, Tellus, 61B, 180-194, 2009. 